\title{
Cuadernos de Ilustración y Romanticismo
} Revista Digital del Grupo de Estudios del Siglo XVIII

Universidad de Cádiz / ISSN: 2173-0687

\section{GONSTRUIR Y RELEVAR A UNA GRAN DAMA DE LA ESCENA: CONCEPGIÓN RODRÍGUEZ Y MATILDE DÍEZ (1800-1836)}

\author{
Guadalupe Soria Tomás \\ (Universidad Carlos III de Madrid) \\ https://orcid.org/0000-0002-0551-2238
}

Recibido: 17-03-2021 / Revisado: 03-04-2021

Aceptado: 29-03-2021 / Publicado: 18-12-2021

Resumen: Este artículo estudia la trayectoria biográfica y artística de Concepción Rodríguez, entre 1800 y 1836. Fue la actriz española más relevante de las primeras décadas del siglo XIX y el modelo en el que se inspiró su sucesora: Matilde Díez. Nos ocupamos de aquellos aspectos por los que fue considerada una gran dama de la escena. En primer lugar, su repertorio, basado, entre otros autores, en las obras de Bretón de los Herreros. En segundo lugar, la recepción crítica, que destacó su sensibilidad, su naturalidad y sus cualidades vocales. En tercer lugar, en los tratados de declamación que recogen como ejemplo su interpretación de Dido, fundadora de Cartago. Por último, en su aceptación social, que se advierte en las composiciones poéticas laudatorias que se le dedican y también en su nombramiento como Maestra honoraria de la Escuela de Declamación Española.

Palabras Clave: Concepción Rodríguez, Matilde Díez, actrices, teatro español del siglo XIX, crítica teatral.

\section{CREATING AND REPLACING A GREAT ACTRESS OF THE SCENE: CONCEPCIÓN RODRÍGUEZ AND MATILDE DÍEZ (1800-1836)}

AвSTRACT: This paper focuses on Concepción Rodríguez's personal and artistic trajectory, between 1800 and 1836. She was one of the greatest Spanish actresses in the first few decades of the $19^{\text {th }}$ century and she became a model and a source of inspiration for her successor: Matilde Díez. We analyse those issues for which she was considered a great actress of the scene. Firstly, we study her drama repertoire that was based, among others, on Bretón de los Herreros' plays. Secondly, we consider the theatre reviews of her performances. These reviews highlight her sensitivity, naturalness and vocal skills. Thirdly, we focus on the treatises on acting that take her performance in Dido, fundadora de Cartago as a model example. Finally, it is considered her status in the society that improves through the poems admirers write for her and thanks to her appointment as Honorary teacher of the School of Spanish Drama.

KeYwords: Concepción Rodríguez, Matilde Díez, actresses, Theatre in Nineteenth-Century Spain, theatre review. 


\section{INTRoducción. ACTRICES EN LAS PRIMERAS DÉCADAS DEL XIX}

Nuestras dos mejores actrices se han despedido con dos beneficios, y han querido dejar antes de su salida de este teatro memorias que se conservarán por largo tiempo; un vacío que no se llenará nunca. La señora Concepción Rodríguez se ha retirado para siempre, la señora Matilde Díez se va de la capital, deja este público que tanto la admira, por recibir nuevos aplausos en Barcelona, y para dejar allí dentro de un año el mismo sentimiento que hoy nos deja; porque la deseamos demasiado para no esperarla, la señora Díez volverá a Madrid para el año que viene. La señora Díez no se acostumbrará a la falta de nuestros aplausos, de nuestra admiración y volverá entre nostoros. ¡Qué no pudiéramos esperar otro tanto de la Señora Concepción Rodríguez!

(Revista Española. Mensajero de las Cortes, 26-III-I836: 668).

José Bermúdez de Castro se dolía, así, en su reseña a la función de beneficio con la que la joven actriz Matilde Díez, contratada para la temporada de I835-36 como primera dama en el Teatro de la Cruz, se despedía del público madrileño. El 24 de marzo de 1836 protagonizó Quiero ser cómico, traducción de Ventura de la Vega de Je serai comédien, de Desnoyer; Clotilde, drama de Soulié, en versión de F. y G. Poza y la pieza en un acto No más muchachos, de Bretón de los Herreros a partir de Scribe y Delavigne. Unos días antes, en el Teatro del Príncipe, Concepción Rodríguez concluía su brillante carrera con Catalina Howard, la traducción de Narciso de la Escosura de la obra de Alejandro Dumas. Se producía una suerte de relevo en el protagonismo escénico, que se desprende de las críticas en la prensa ya desde el año cómico anterior.

No fue esa una temporada teatral sencilla, como tampoco lo fueron las de las décadas precedentes. El teatro sufrió, igual que otros ámbitos, los avatares de la convulsa coyuntura política — de la que también fue instrumento de propaganda (Palacios y Romero Ferrer, 2004: I85-242; Freire, 2009; Rodríguez Sánchez de León, 20I2: 40I-428) - y la inoperante gestión del Ayuntamiento, su responsable último, y la de las empresas que se sucedieron desde inicios del XIX — bien de particulares bien bajo el gobierno de un actor, de una agrupación de actores o del propio Ayuntamiento, cuando terminaba asumiéndolas- (Martín, I985: I23-I3I y 1988: 209-222; Gies, 1996; Catalán, 2002: III-I30; Fernández Cabezón, 2013: 105-120).

A pesar de estas dificultades de orden político y económico-administrativo, el teatro de las primeras décadas del siglo, en el que circunscribimos nuestro artículo, conoce una serie de cambios y mejoras fundamentales en el ámbito artístico. El repertorio revela, por un lado, un gusto por el teatro vocal, que impulsará la apertura, en 1830, del Real Conservatorio de Música de María Cristina; por otro, una clara dependencia de la cartelera francesa, a partir de la que se traducen comedias, vodeviles, dramas, melodramas y tragedias de, por ejemplo, Scribe, Dumas, Víctor Hugo, Ducange. Se desarrolla, además,

I Mi agradecimiento a D. Rubén Campos, de la Biblioteca Pública de Palma. Can Sales, y a D. José Jiménez, de la Bibliotheca Sefarad, por permitirme el acceso al Almanaque balear para el año de I884 que contiene la primera transcripción de la partida de bautismo de la actriz Concepción Rodríguez; al equipo técnico de la Biblioteca Nacional de Catalunya, al profesor Biel Sansano, y a Da Rosa Aguilar y D. Josep Pol, del Archivo Diocesano de Mallorca (ADM). Además de la anterior, las abreviaturas de centros y archivos que se referencian en este artículo son: AGA (Archivo General de la Administración), AGP (Archivo General del Real Palacio), AHN (Archivo Histórico Nacional), AHPM (Archivo Histórico de Protocolos), ARCSMM (Archivo histórico-administrativo del Real Conservatorio Superior de Música), APSSM (Archivo Parroquial de San Sebastián de Madrid), AVM (Archivo de Villa. Madrid), BNE (Biblioteca Nacional de España. Madrid), MNT (Museo Nacional del Teatro. Almagro) y RAE (Real Academia Española). Modernizo, como criterio general, la ortografía de las fuentes citadas. En casos muy puntuales dejo las mayúsculas por su valor enfático. 
la comedia de corte moratiniano, gracias a Bretón de los Herreros o a Ventura de la Vega, quienes junto a, entre otros, Larra, García Gutiérrez y Juan de Grimaldi son responsables de no pocas de estas traducciones y del avance de la crítica teatral (Rumeau, 1939:330-346; Leslie, I940; Menarini et al., I982; Lafarga, I983; Gies, I985: I13-I22; Dengler, I991: I6I-I69; Ballesteros Dorado y Cruz, 20I5: I6I-I80). A partir de I835, esta programación convive con los dramas románticos, que acentúan el patetismo de la comedia lacrimosa y lo espectacular de los melodramas (Pataky Kosove, 1978: I02-136; García Garrosa, 1990; Ribao, I999; Coca Ramírez, 2000: II5-I30). Grimaldi — pionero de la figura moderna del director de escena y responsable de la adaptación del texto mejor acogido del periodo estudiado, la comedia de magia Todo lo vence el amor o La pata de cabra - dirige los estrenos de Don Álvaro, del duque de Rivas; La conjuración de Venecia, de Martínez de la Rosa; Macias, de Larra o El trovador, de García Gutiérrez, cuyas protagonistas interpreta su esposa, Concepción Rodríguez. A partir de septiembre de 1823 , cuando se hace con la empresa de los teatros de Madrid, configurará un repertorio coherente, que responda al gusto del público burgúes, e impulsará una renovación en el trabajo de los actores, que les permita adaptarse al lenguaje que requieren los nuevos textos (Duffey, I942: I47-I56; Gies, I988).²

La necesidad de formarlos —uno de los temas centrales del debate sobre la mejora escénica del Xviı (Álvarez Barrientos, I988: 445-366; Soria Tomás, 2009: 9-32)— aparece en las tres propuestas presentadas por particulares al Ayuntamiento para conseguir la empresa de los teatros de la temporada siguiente. Las exposiciones de Grimaldi, fechadas en marzo de 1824, son las más ambiciosas. Denunciaba el abandono de la declamación, del que exceptúa a Isidoro Máiquez. Se comprometía a establecer una escuela en uno de los dos teatros durante tres años, tiempo que duraría la contrata. Las enseñanzas las impartiría,junto con dos profesores españoles, tres veces a la semana y estarían destinadas tanto a los actores de la compañía española como a los alumnos externos autorizados por el Corregidor. Con ellas buscaba que el actor diferenciara entre la declamación en prosa y en verso, conociera el concepto de verdad relacionado con la naturaleza, la diferencia de los distintos tipos de personajes y el conocimiento de las pasiones. Se trataba de distinguir a los «verdaderos cómicos» de los «meros recitantes» (AHN, Consejos, Leg. II4II, no 35; Soria Tomás, 2008: I8I-I87; Álvarez Barrientos, 2019: 345-346). Por decisión del Ayuntamiento, la empresa recayó en el actor y cantante Antonio Campos. La institucionalización oficial de las enseñanzas actorales se verificó en I83i, con la apertura de la Escuela de Declamación Española dentro del Conservatorio ya referido. Esta contribuyó a la rehabilitación social de los actores y actrices, pues venía a considerar su oficio - tradicionalmente vil e infame- como un arte liberal y a premiar a sus profesionales más destacados con el nombramiento de Maestro honorario, reconocimiento que Concepción Rodríguez recibió en I835 (Chancerel, 1930; Larraz, I980: 27-40; Martin-Fugier, 2008: 19I-277 y 3II-350; Soria Tomás, 2010: 409-422).

Ese mismo año, Grimaldi firma, con la sigla A - Aquiles, como le apodaban en los círculos teatrales (Gies, 1988: 136) - , una semblanza de la actriz en El Artista (1835: 193I96), que se abre con una litografía de Federico de Madrazo. Presenta un breve recorrido por la primera etapa de su trayectoria biográfica y artística — con algún error, por ejemplo el de la fecha de su nacimiento, que corregiremos- y describe varios defectos técnicos.

2 Solo consiguió la empresa propiamente durante esa temporada de 1823-24, aunque ejerció de director en varias de las siguientes, hasta que regresó a Francia, su país natal, en agosto de I836. Pueden seguirse las vicisitudes de las distintas propuestas de empresas desde I824 a I836 tanto en Ballesteros Dorado (20I2, I: I7-II2, I47-I59, 22I-227, 3093І6, 393-396, 529-532, 553-557, 567-572, 699-7I3 y 20I2, II: I3-23, II7-I24, I99-203, 299-306) como en Gies (I988: 22-I34). Este último, para su monografía de Grimaldi, sigue, con frecuencia, el trabajo de fin de estudios de B. Desfrétières, Jean-Marie de Grimaldi et l'Espagne (Faculté de Lettres de Paris, 1962). 
El texto puede leerse como una declaración programática en la que ejercitar a los actores, acorde con los objetivos del memorial de I824 para renovar la empresa. De sus interpretaciones más aplaudidas en los primeros años en Madrid, las críticas destacaban su voz, a la que no obstante: «faltábale extensión, mordiente» pues «no se prestaba a la completa expresión de las variadas pasiones que una primera actriz está destinada a pintar». Poseía sensibilidad, aunque «exageraba a veces su expresión, y no sabía distribuirla con la prudente economía que el arte enseña y la experiencia revela». Se detiene también en criticar el tono llorón y en el detalle poco natural de sacar el pañuelo para resolver las escenas patéticas. Vicios de actriz novel, indicaba, que no distingue entre los matices de las emociones:

confundía en común expresión afectos muy distintos aunque análogos, como, por ejemplo, la melancolía, la tristeza, la aflicción, la pesadumbre; daba frecuentemente al candor el colorido de la bobería; tomaba a veces al pie de la letra la calificación de niña dada a algunos de sus papeles, y aniñaba demasiado su representación [...] (A., 1835: 195).

En definitiva, carencias que enmendó gracias a su inteligencia, aplicación y estudio, que el sistema de empresas favorecía, según Grimaldi, frente al tradicional que dificultaba la ascensión de las jóvenes más prometedoras dentro de la estructura jerarquizada de las compañías.

El objetivo de nuestro artículo es estudiar la trayectoria artística de Concepción Rodríguez, para comprobar cómo se configuró en primera dama de la escena y cómo se produjo su relevo, en este caso por Matilde Díez. El artículo se divide en dos grandes apartados. El primero se detiene en su genealogía y carrera escénica hasta I832, en el que no firma contrata para Madrid. El segundo recoge sus tres últimas temporadas. En la de 1833-34, tras un dilatado proceso para decidir sobre la empresa, Concepción Rodríguez protagoniza un escándalo a propósito de la representación del sainete El joven de sesenta años. Se frustra, por otro lado, el embargo de Matilde Díez, entonces en Sevilla. Durante la siguiente, I834-35, se contrata a esta última para los papeles de segunda dama, que suele desempeñar en el Teatro de la Cruz. En el próximo año cómico, figura ya como primera, mientras Concepción Rodríguez estrena sus últimos grandes éxitos y solicita retirarse. A la consolidación de Matilde Díez contribuye una aplaudida temporada en Barcelona.

Sustentamos esta investigación en fuentes hemerográficas - esenciales para conocer la cartelera, los repartos y la recepción práctica del teatro- - y archivísticas; además de con la bibliografía crítica de referencia. Nos detendremos, también, en una selección del repertorio que interpretaron. Abunda, por ejemplo, el personaje de la histérica o de la afectada por arrebatos más o menos transitorios de enajenación, pasión o locura —que permitía grandes momentos interpretativos- (Ribao, I999-2000: I85-200; Gies, 2005: 215-225). De otro lado, el modelo femenino que presentan muchas de estas obras responde a la imagen de la mujer abnegada (Gies, 2009: I08-I2I), según el rol aceptable en la esfera pública burguesa (Mornat, 2008: 447-458), aunque no exclusivamente, como demuestra, por ejemplo, el estudio de Caldera sobre las heroínas románticas más representativas (Caldera, 2005: 57-63). Tampoco, ya lo ha señalado Barba Dávalos (20I4: sp) en respuesta a las afirmaciones de Mornat, las críticas se centraban sobre todo en aspectos relacionados con la sensibilidad obviando cuestiones técnicas asociadas al ejercicio de la inteligencia que se dirigirían a sus colegas varones. De hecho, en muchas de las reseñas se describe la pericia de las actrices en mayor proporción que la de los actores. Sensibilidad e inteligencia figuran tanto en las críticas destinadas a estas dos actrices como en las referidas a otras 
compañeras durante el periodo estudiado. Son, además, dos de las cualidades de las que, según la preceptiva de los tratados de declamación de la época, debía disponer un actor, independientemente de su sexo (Latorre, I839: 13-21; Bastús y Carrera, I865: I6).

La reconstrucción de estas trayectorias confirma el teatro, igual que otras artes - la música, la escritura, en menor medida la pintura - como uno de los pocos espacios públicos con presencia femenina activa en el siglo xix (Anderson y Zinsser, I992: I94-226; Rabaté, 2007: 226). Es esta una cuestión relevante por cuanto el estigma que acarreaba la profesión desde sus orígenes, más virulento contra las actrices (Rodríguez Cuadros, I998: I25-312 y 573-658), se irá desplazando hacia determinadas bailarinas o las artistas de variedades (Sánchez, 2019: II6-I4I). Este proceso de rehabilitación en la sociedad pública, que Duvignaud sitúa en el paso de las sociedades liberales a las modernas (I966: I27-210), fue lento y en él las actrices — que, en ocasiones, aparecen como personajes escénicos (Miret i Puig, 2005: 253-260) - debieron moverse entre la doble proyección público-privada de su persona, como explicó la actriz Balmaseda a finales de siglo (I881: 63-77).

\section{Concepción Rodríguez: Genealogía de una primera dama (i80o-I832)}

María de la Concepción Rodríguez Abril nació el i4 de diciembre de i8oo en Palma de Mallorca y se le bautizó al día siguiente en la Catedral. ${ }^{3}$ Pertenecía a la Parroquia de San Miguel, muy cercana al teatro de la ciudad — antigua Casa de Comedies (Garcías Estelrich, 2005; Esteve, 2008: 39-54)—, en cuya compañía trabajaba gran parte de su familia. Su padre, Bruno Rodríguez, natural de Torrenueva, aparece contratado como segundo galán en las listas del teatro desde $1802 .{ }^{4}$

Rosa Abril Hinojosa, originaria de Córdoba, pertenecía, al parecer, a una familia acomodada venida a menos a consecuencia de la Guerra del Rosellón. Tuvo que hacerse cargo de sus tres hermanas menores: Rosalía, Josefa y Concepción, quienes se dedicaron al teatro. Adoptaron el apellido Velasco quizás de algún pariente lejano, pues figura en algunos documentos oficiales. Según la necrológica dedicada a Concepción Velasco ( $\mathrm{La}$ Revista Española, I9-XII-I832: IO2-IO3), comenzaron en el Teatro de Reus alrededor de 1795. Tenemos documentada a Josefa Velasco como quinta dama, para I80o, en el Teatro de Valencia, al que llegó desde Tortosa (Diario de Valencia, I6-IV-I80o: 6I). De ahí pasaría a Palma, donde en 1802 es cuarta dama. Su hermana Rosalía está contratada como primera. Tanto Rosalía como Bruno mantienen sus respectivas categorías hasta I805; temporada en la que Josefa es sobresaliente. Un episodio un tanto oscuro protagonizado entre los actores y el empresario, Joan Pau Sastre, termina, en mayo de i805, con Rosalía en prisión. Concluida la temporada, la actriz solicita permiso para contratarse en otro

3 El error del comúnmente aceptado de 1802 podría deberse a los datos que figuran en su partida de matrimonio, que transcribiremos más adelante. Eusebio Pascual hizo lo propio con la de su bautismo en el Almanaque balear para el año de 1884 donde presentó una breve biografía de la actriz que sigue, a grandes rasgos, la semblanza publicada por Grimaldi en El Artista. No obstante, incluye alguna apreciación sutil, como el que las críticas que recibió resultan, a veces, contradictorias (Pascual, I883: I37-I46). También da la fecha correcta el Diccionari del Teatre a les Illes Balears (Mas i Vives, 2006: I65). La partida dice así: «Hoy día I5 Diciembre año I8oo yo el Dr. Mathias Alemany asistente de Domº bauticé una hija de Bruno Rodigues [sic], y de Rosa de Abril consortes que nació a las siete de la tarde del día antecedente: fue su nombre María de la Concepción Antonia Josefa Raymunda Llull, Catharina Thomas María del Carmen Agustina Rosa Buenaventura: son sus abuelos paternos Eulogio, Ignacia Mayol: los maternos Antonio y Bernadina de Hinocoza [sic]: fueron Padrinos Josef Estoracio, María Baldez. Es de S. Miguel» (ADM, Catedral, $\mathrm{B} / 25, \mathrm{f} .75)$. El I de marzo de 1803 nació su hermano Manuel, bautizado, al día siguiente, en San Nicolás; el 4 de febrero de I8o6, su hermano José, al que bautizaron en San Jaime (ADM, I/49-B/24, f. 36 v, no I9 y I/47-B/2I, ff. 47 v-48, no 8; Esteve, 2008: 287).

${ }_{4}$ No se conservan las listas de actores para la compañía del Teatro de Palma de la temporada I8oo-I8or y siguiente, pero podría estar ya ajustado. Para las de Madrid son muy útiles los manuscritos MNT, Doc. $345^{2}$ y RAE, Ms. 363. 
destino. Ningún miembro de la familia consta en las listas del teatro palmesano para la temporada de i806. Según la documentación que se conserva, la primera dama estaba, por aquellas fechas, enferma (Esteve, 2008: I37, I45, I54-I58). Rosalía y Josefa pudieron fallecer al poco tiempo. Así lo suguiere la necrológica indicada. No hemos localizado sus nombres en listas posteriores en las que figuran Bruno Rodríguez o Concepción Velasco. Esta última fue primera dama de la compañía del Teatro de Valencia en $\mathrm{I}_{\mathrm{O}} 2$ - a donde llegó desde Cartagena—, I803, 1805 — tras su paso por Zaragoza—, y 1806, año en el que su cuñado se une a esta compañía en la categoría de sobresaliente (Diario de Valencia, 24-IV-I8O2: I05-IO6; 5-IV-I8O3: I7-I8; I3-IV-I805: 52; 6-IV-I8O6: 23-24). Para la temporada próxima, Concepción Velasco se ajusta en el Teatro del Príncipe de Madrid; después se contrata en Sevilla. Bruno Rodríguez sigue esa temporada en Valencia (Diario de Valencia, 28-III-I807: 350-35I; 3I-III-I807: 36r; MNT, Doc. 3452; Cotarelo y Mori, 2009: 53I). En I8I4 figura, de nuevo, en Palma y regresa a Valencia para el siguiente año cómico. Su cuñada hará el camino inverso, pues en I8r5 pasa a Palma. En la temporada de i816-I7, el actor se ajusta en Barcelona para suplir al primer galán (Diario de Valencia, 25-III, I8I5: Ir6; Diario de Barcelona, I8-IV-I816: 533; Esteve, 2008: 206 y 2I4). Al año siguiente, la compañía incluye a Concepción Velasco, contratada como matrona de carácter — papel en el que se especializará-, y a Concepción Rodríguez, como segunda dama, jerarquía que comparte con Juana Galán y Jerónima Llorente. Entre los cómicos se encuentra José Robreño. El director es Andrés Prieto, uno de los actores, junto a Máiquez, más relevantes de las primeras décadas del siglo (Diario balear, II-IV-I8I7: 2-3; Suero Roca, I990; 3I-32; Soria Tomás, 2020a: 165-187).

Concepción Rodríguez se ajusta como segunda dama del Teatro de la Cruz en I8I8. Así figura en las listas de actores de ambos teatros que acompañan al reglamento del Juez Protector de Teatros, José Manuel Arjona. Cada coliseo tendría su compañía de verso, encabezada por el primer galán, responsable de la parte artística. Una única compañía de ópera se repartiría entre los dos (Cotarelo y Mori, 1904: 718-722). Ahí trabajó bajo la dirección de Bernardo Gil, cuya mujer, Antera Baus, se reparte los papeles protagonistas con Manuela Carmona. Cobran, igual que los primeros galanes - Juan Carretero y Antonio González - 40 reales diarios. Concepción Rodríguez tiene asignados 15. En la compañía del Príncipe, Isidoro Máiquez y Andrés Prieto, con quien había trabajado en Barcelona, son los primeros galanes. Se mantiene en esa misma categoría y teatro en las siguientes - con ligeros aumentos de sueldo-. Asciende a primera actriz, con la empresa de Sáenz de Juano, en la temporada de I822-23 (MNT, Doc. 7145 y Doc. 3452).

La prensa ya recoge noticias de esta, que podríamos considerar, su primera etapa profesional. Algunas, centradas sobre todo en el trabajo de la actriz principal, Antera Baus, incluyen breves apuntes interpretativos que responden a fórmulas genéricas. Es el caso, por ejemplo, de su contribución a La Toquera vizcaína, comedia de Juan Pérez de Montalbán, en la que «La señora Concepción Rodríguez, la señora González, y demás partes que han desempeñado los primeros papeles, lo han hecho regularmente» (El Universal, 28-vIII-1821: 924) o a La villana de Vallecas, de Tirso de Molina, que resuelve «con las gracias que acostumbra» (El Espectador, I3-VIII-I82I: 484). En su actuación en otra obra de Tirso, Por el sótano y el torno, ambas en refundición de Dionisio Solís, la crítica afirma que las actrices: «han desempeñado sus respectivos papeles con una maestría y un donaire sorprendente» (El Universal, I3-IX-I821: 984). El Imparcial, por su parte, destaca un momento preciso de la actuación de la primera y segunda dama, muy bien recibida por el público: «La representación fue brillante: las señoras Baus y Rodríguez obtuvieron aplausos repetidos y justamente merecidos: señaladamente en la escena en que la viuda riñe a su hermana por haber tropezado en la calle, y en el monólogo en que se decide a 
renunciar a su viudeZ» (I2-IX-I82I: I2). La crítica, no obstante, denuncia la falta de profesionalidad de otra parte del elenco, que no domina el texto. Más elaboradas son las que se detienen en sus interpretaciones de Inés, en La bija en casa y la madre en la máscara, de Martínez de la Rosa, y, en especial, los elogios por Paquita, en El sí de las niñas, de Moratín.

Gertrudis Torres, la graciosa Rafaela González, Juan Carretero, Rafael Pérez y Concepción Rodríguez protagonizaron esta reposición de La hija en casa y la madre en la

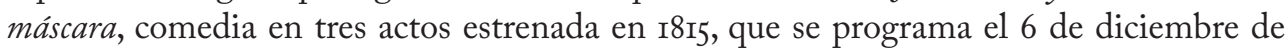
I82I. La reseña, que alaba el texto y la interpretación en su conjunto, destacó el buen hacer, la sensibilidad y el manejo de la representación emocional de la joven, y precisaba que:

Es imposible dar una idea exacta de la maestría y talento con que la señora Concepción Rodríguez ha desempeñado el papel de Inés: esta preciosa actriz manda los afectos de los espectadores, arranca lágrimas cuando llora, provoca odio cuando ella representa que lo tiene, excita la risa cuando ríe; y no hay pasión que no agite cuando se empeña en hacer olvidar a sus admiradores el mérito de otras buenas actrices que tanto lucen en la escena: en la que tiene al fin del tercer acto con Teodoro cuando le aconseja la fuga, ha tenido golpes magníficos que más recuerdan a la divina Rita en la Misantropía (El Espectador, II-I2-I82I: 968).

Junto a la retórica que enlaza con la máxima de la poética horaciana — si uis me flere, dolendum est / primum ipsi tibi (vv. IO2-IO3) - y con el dominio que Cervantes, por boca de Pedro de Urdemalas, señalaba para el perfecto recitante, se establece un vínculo con la prestigiosa Rita Luna. La interpretación de Paquita, un carácter de joven sumisa e inocente, similar al anterior y compatible con los patrones femeninos señalados más arriba, es también muy bien recibida por la crítica en varias de las reposiciones que se suceden durante el Trienio Liberal, cuando se levanta la prohibición inquisitorial que pesaba desde 1815 sobre varias obras de Moratín (RAE, Ms. 363, ff. 46 r-63 r, Doménech, 2003: I59). El reseñista de El Universal se detiene en las tres actrices, sin especificar el nombre de los actores. Destaca la comicidad de Rafaela González, la solvencia de Josefa Virg, que interpreta a Doña Irene, y, en especial, la resolución de Concepción Rodríguez. Su naturalidad y sencillez, sin caer en la ñoñería, así como la sutileza en varias de las réplicas con Don Diego, que revela, de nuevo, su capacidad para resolver y transmitir distintas emociones, le auguran un brillante porvenir:

Su dolor al saber la ausencia de D. Carlos se transmitió a todo el auditorio, y la propiedad con que figura en el diálogo con D. Diego querer ocultar su aflicción y su abatimiento, excitó un general aplauso. Sobre todo cuando aquel le pregunta ¿qué siente Vd? Y ella contesta, no es nada... así un poco de...nada...no tengo nada; apenas hubo quien no diese señales evidentes de aprobación. Si esta actriz continúa aplicándose, si no se envanece con los elogios de la luneta, y si procura merecerlos cada vez con mayor mérito, será quizá algún día uno de los principales adornos de nuestra escena (25-VII-I82I: 808).

El Eco de Padilla, en la reseña a El Barón (3-IX-I821: 269-271), comenta los logros de la actriz y aplaude que se repartan los protagonistas en función del mérito y adecuación física de los actores con respecto al perfil y la edad de los personajes, en vez de atender a 
la tradicional jerarquía de las compañías. ${ }^{5}$ Un año más tarde, en El Indicador (Io-IX-I822: 651-652), vuelve a reseñarse una de sus actuaciones en El si de las niñas, probablemente por el mismo autor de El Universal, que le insta a perfeccionarse en el estudio de los papeles y a ampliar el registro de su repertorio. Los argumentos son muy similares a los esgrimidos por Juan de Grimaldi en su reseña biográfica.

Grimaldi, tras la quiebra de Sáenz de Juano y después de hacerse en septiembre de I823 con los teatros, se dedicará, entre otras mejoras relativas a la escena, a cumplir con este doble objetivo: perfeccionar a la actriz — con quien contrae matrimonio en enero de $1825-^{6}$ y configurar un repertorio mucho más ambicioso. Como ha señalado Gies, su presencia en papeles protagonistas se incrementa a partir de la temporada de $1825-26$. Entre el 3 de abril y el 20 de septiembre, participa en diecisiete títulos distintos que suben a escena en cuarenta y seis funciones. Regresa al teatro en agosto de 1826 - tras dar a luz a su primera hija, Clotilde, en el mes de diciembre anterior-y hasta final de año actúa en otras noventa funciones de veintinueve obras diferentes. Entre ellas, encontramos dos de los títulos que repondrá con más éxito: El abate L'Epée o La huérfana de Bruselas, de Ducange, en traducción del propio Grimaldi, estrenada el 6 de julio de 1825 , y Dido: fundadora de Cartago, quizás una de sus interpretaciones más alabadas, que estrena el 23 de octubre de I826; ambas en el Teatro del Príncipe (Gies, I988: 4I-45 y 2002: 309-3I8). Bretón de los Herreros le dedicó su traducción de esta tragedia original de Jean-Jacques Lefranc.7 También hizo lo propio Dionisio Solís, cuya versión de Camila, a partir de Los Horacios de Corneille, estrena el 23 de abril de i828, de nuevo en el Príncipe. ${ }^{8}$ Una reseña, es muy posible que de Carnerero, en El Correo Literario y Mercantil (25-VII-I828: 2), destaca al elenco masculino, encabezado por Caprara, Montaño y Latorre. Reconoce, además, al detenerse en un fragmento especialmente dramático del acto cuarto, los avances que se detectan en la actriz que:

ha manifestado cuanto se debe expresar de la exquisita sensibilidad con que la ha dotado el cielo, y cuanto del estudio y aprovechamiento con que ha sabido en esta ocasión modular y aumentar su voz. Las menores acciones, los más leves movimientos que ha ejecutado en esta tragedia, se conoce que han sido hechos con acertado estudio y, por consecuencia, con oportunidad y con placer del espectador.

${ }_{5}$ Cuestión que venían reivindicando los partidarios de la reforma escénica desde el siglo anterior.

6 Se celebró en la Parroquia de San Sebastián. La partida dice así: «En once de enero de mil ochocientos veinticinco: con mandamiento del Sr. Dn. Francisco Antonio de Macorra, Presbítero Teniente Vicario Eclesiástico de esta Villa de Madrid y su Partido, ante José María Patón, Notario, su fecha diez del mismo mes y año, habiendo precedido los requisitos prevenidos por la Real Pragmática, e igualmente dispensa de las tres amonestaciones que el Santo Concilio manda por dicho Sr. Teniente Vicario, y no resultado impedimento alguno: Yo D. Francisco Ruiz, Presbítero Teniente Cura de la Iglesia Parroquial de San Sebastián de esta Corte, después de haberlos examinado, y hallándolos capaces en la Doctrina Cristiana: Desposé por palabras de presente que hacen verdadero y legítimo Matrimonio teniendo sus mutuos consentimientos, y vele in facie ecclesiae a D. Juan María Grimaldi de edad veintinueve años, empleado, natural de la ciudad y arzobispado de Aviñón en el Reino de Francia, hijo de D. Pedro Grimaldi y de $\mathrm{D}^{a}$ María Contamien, mayor de veinte nueve años: con Da María de la Concepción Rodríguez de edad de veintitrés años, natural de la Isla de Palma de Mallorca hija de D. Bruno Rodríguez y de Da Rosa Velasco la cual ha obtenido el consentimiento de sus Padres: fueron testigos D. Alfred Aquiles Maroien, D. Agusto Lafón, D. Manuel Rodríguez y Juan Jiménez y lo firmé = D. Francisco Ruiz=» (APSSM, Libro 38 de matrimonios, f. 276v).

7 «A la Señora Concepción Rodríguez, primera actriz del teatro del Príncipe. El público, a quien tan gratas sensaciones ha ocasionado la digna intérprete de Dido, Andrómaca, y La huérfana de Bruselas, verá sin duda con placer al frente de esta obra el nombre de la actriz que tanto honra a la escena española, y cuya amistad envanece a su efectuoso servidor» (Bretón de los Herreros, 1827: sp).

8 «A la Señora Concepción Rodríguez, primera actriz del Teatro del Príncipe. El agradecimiento y la amistad de Dionisio Solís» (Solís, I828: sp). 
Confesamos con mucho gusto que hemos notado grandes adelantos en esta joven, que tanto prometió desde el principio de su carrera.

Amplía el repertorio, son solo unos ejemplos, con orignales u otras traducciones de Bretón de los Herreros: Maria Estuarda —original de P. A. Lebrun y estrenada en 7 de noviembre de 1828 - o El colegio de Tonnington o La educanda - a partir del original de Ducange y Bourgeois-, presentada en la temporada teatral de 1830-3I en la que actúa en Sevilla (Aguilar Piñal, I968: I6-I7; Gies, I988: 87-92; Ballesteros Dorado, 20I2, I: 557-560). Salvo esta y las de 1827-28, 1829-30 y 1832-33, cuando se retira momentáneamente o bien trabaja en provincias, Concepción Rodríguez figura como primera dama de los teatros de Madrid. En 1826, percibe una remuneración mayor que el resto de actrices con las que comparte esta categoría - Antera Baus y Agustina Torres- (MNT, Doc. 3452; RAE, Ms. 363).

De sus actuaciones en Sevilla da cuenta Bretón de los Herreros, quien le dedica varios poemas. Así, el soneto «A la Señora Concepción Rodríguez, primera actriz de los teatros de Madrid, con motivo de haber pasado al de Sevilla en el año 1829" vaticina la momentánea orfandad en que quedará, por su partida, la escena madrileña (Bretón de los Herreros, I831: I83):

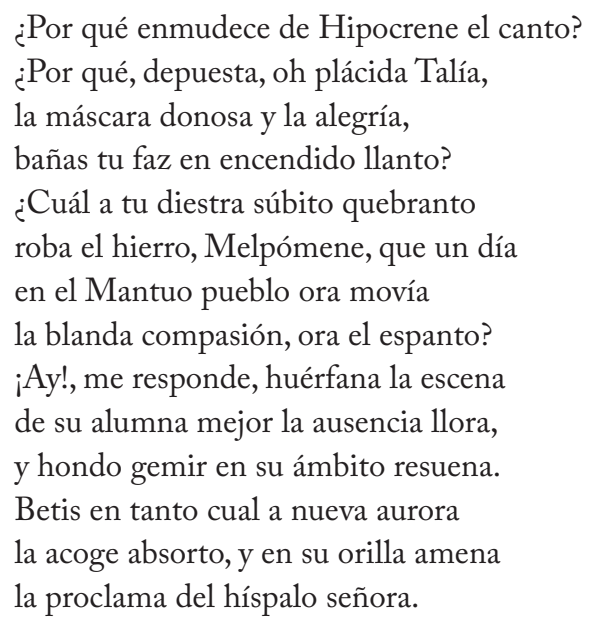

Ya en Sevilla, y con motivo de una función de beneficio, compone el siguiente epigrama: «Apenas tu papeleta de beneficio leí / dije, oh Concha, para mí: / tú se lo harás al poeta / aun más que el público a ti» (I831: 192). Una primera versión de su más ambiciosa Oda III «El teatro. A la admirable actriz Concepción Rodríguez», donde el dramaturgo vuelve a vincular su producción con el talento de la actriz, motor que le inspira (I83: I2-I4), circula por la ciudad. El Correo (29-XII-I830: 2), que informa de sus éxitos, reproduce las siguientes estrofas, en las que la pericia de la primera dama se inserta en una genealogía de prestigiosos primeros actores:

¡Y cuál es, oh teatro,

Tu mágico poder cuando concedes

Al sacrosanto coro de Helicona

Intérprete feliz! Por siempre avara

De tan sublime don naturaleza,

¡Cuán rara vez al mundo le depara! 


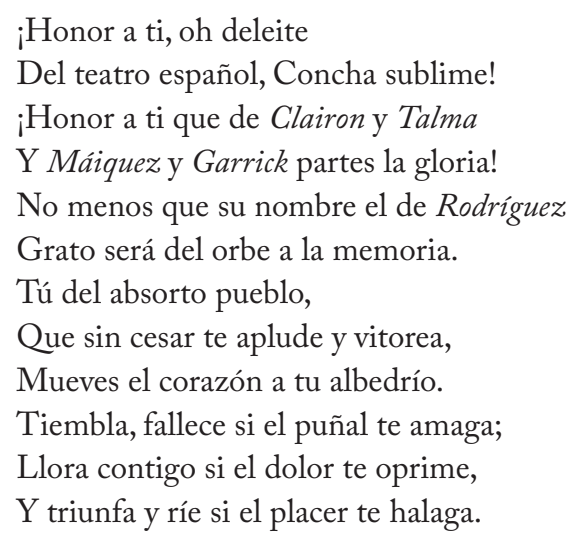

Tanto este como Carnerero anunciaron el regreso a Madrid de la compañía de Grimaldi y, por tanto, de Concepción Rodríguez, para la temporada siguiente. En ella, su tía, Concepción Velasco, continuará como característica, hasta su muerte en diciembre de 1832. Bruno Rodríguez, contratado para los papeles de anciano en Barcelona durante la temporada de 1829-30, se ajustó también en el Teatro del Príncipe en esta categoría, que desempeñó hasta la de 1840-4I, en que falleció (Suero Roca, 1997: 76; MNT, Doc. 3452).

Ambos escritores reseñan, además, la reposición de Camila, que Concepción Rodríguez protagoniza el i8 de junio de i83 r en el Teatro del Príncipe. Carnerero en Cartas Españolas, revista que incluye un nuevo soneto dedicado a la actriz donde sobresale la excelencia de su voz «Con inflexión tan dulce y tan süave» y su expresividad que «Retratar el placer, o el llanto sabe» (Cartas Españolas, ro-VI-I831: I76), describe la buena acogida del público y destaca, en la línea de los testimonios que estamos viendo, su sensibilidad e inteligencia, para afirmar que si: «sigue presentando tales muestras de sus progresos, será el diamante de la escena española. Este hermoso título, aunque se le dé desde ahora, no será inoportuno ni indebido» (25-VI-I83I: 215).

Por otro lado, la extensa crítica de Bretón de los Herreros para El Correo Literario y Mercantil —apareció el 22 de junio-, recoge este terceto que Solís habría estampado en un ejemplar del texto dedicado a la actriz: «Tú, honor de la Melpómene española, / Con tu nombre ilustrar el de Camila, / Pues que le diste el ser, mereces sola» (Bretón de los Herreros, 1965: 77). Precisa la cuidada dirección de Grimaldi sobre todo el conjunto del espectáculo «dispuesto y ensayado con esmero»; del elenco masculino destaca a Joaquín Caprara, que interpreta a Publio, y a Carlos Latorre, que actúa a su hijo Horacio. Son los romanos enfrentados al albano Curiacio, esposo de su hermana Camila, quien morirá a manos de Horacio. La tragedia ofrece momentos de lucimiento a la actriz, que se debate entre el patriotismo y la fidelidad amorosa. El reseñista describe con precisión los que considera más sobresalientes. La ternura con que declama varios pasajes del acto segundo —en concreto II, 3 (Solís, I828: 26) —, le llevan a afirmar:

¿Y qué expresiones serán suficientes para encarecer el peregrino talento que, como nunca, ha manifestado esa Concha prodigiosa, cuyos acentos, cuyas actitudes, cuyas miradas son otras tantas perlas inestimables? Madrileños, que acabáis de aplaudirla con tanto entusiasmo, decidme si son exagerados mis elogios; si los dicta la amistad o la justicia (1965: 78). 
Destaca la «verdad», ${ }^{9}$ la «amargura» con la que resuelve los parlamentos y, en particular, cómo interpreta la desesperación a lo largo de la tensa escena que mantiene con su hermano y esposo - III, 6 (Solís, I828: 46-52) - «Pero cuando se interpone a Horacio y Curiacio, desesperada, frenética, pidiéndoles por favor la muerte, no hay quien se resista a la magia de sus acentos, a la expresión de su rostro terriblemente dolorosa» (Bretón de los Herreros, 1965:78). El público aplaude su salida de escena en Iv, 4 - los versos que incluye Bretón para señalar este mutis difieren del original (1965: 78; Solís, 1828: 62)—. Con todo, destaca la pericia de la actriz al darse muerte - desviación con respecto al texto de Corneille, donde muere a manos de su hermano-, pues «ni es concedido a un genio menos privilegiado que el suyo el pintar como lo hizo las agonías de una muerte sangrienta». Tras atravesarse con la espada de Horacio, debía proferir el siguiente fragmento mientras agonizaba (Solís, 1828: 76-77):
¿Eres tú, padre mío? [i] ah! No me mires
Con ceño, no... si a Roma el amor mío
Pudo ofender, la pena que me impuse
La deja satisfecha... fui culpable;
Pero muero... Perdóname... en el reino
De las sombras estoy... aquí no es crimen
Amarte, esposo mío... pero, [i] ay!... mira...
Horacio es que te sigue... iqué de sangre
Corre!... y el fiero con la espada... jo furias!
Acudid en su amparo... interponeos
Para que no le mate... ay triste. (Muere).

El final de esta tragedia presenta una situación análoga con Dido, pues la protagonista también muere tras herirse con un puñal. Como ha señalado Ballesteros Dorado, parece que la actriz era especialmente hábil en resolver estas situaciones dramáticas. Es posible que el cambio que esta investigadora ha observado en los apuntes del estreno de Dido con respecto a la versión impresa se deban a una decisión del director (Ballesteros Dorado, 2OI2, I: 274-275; Bretón de los Herreros, 1827: 6I-62). En la praxis, invertir la acción —decir el parlamento y después herirse-, propiciaría una solución más «natural» para la actriz que evitaría, quizás, derivar en lo ridículo.

Es esta interpretación la que centra la crítica que Luis Lamarca dedica a la actriz tras su paso por el Teatro de Valencia en el mes de julio siguiente. $\mathrm{El} 7$ de julio presenta Dido (Diario de Valencia, 7-VII-I83r: 40). Protagonizará también, al menos, La buérfana de Bruselas y la pieza en un acto, nueva traducción de Bretón del original de Dieulafoy, Desconfianza y travesura o A la zorra candilazo, pues reseña las tres en el número del I7 de julio del Diario de Valencia (9I-96). La actriz era capaz de desenvolverse con soltura en los distintos géneros «he aquí el colmo de la perfección, he aquí lo que constituye el verdadero cómico y lo distingue del simple actor: el talento de apropiarse los caracteres más opuestos» (95). Sobre La buérfana de Bruselas señala su dominio de las escenas más patéticas, por ejemplo, en su reacción ante la amenaza de Walter de apuñalarla, cuando

9 Sobre la idea de verdad, de naturalidad, de realismo o la tendencia sentimental del actor en el xix han reflexionado, entre otros, Rubio Jiménez (I988: 257-286) y Álvarez Barrientos (2009: 286 ss.). No dejan de ser nociones, como la de verosimilitud, en cierta medida problemáticas por la historicidad de su significado en el que, como señaló Melendres (2000: I4I-I42), no solo están implicadas cuestiones artísticias sino también de carácter moral. 
el espanto que se apoderó en aquel acto de toda su existencia, el horror pintado en su semblante, la agitación y feliz desorden de su persona, su grito penetrante y sobre todo, el modo noble con que cayó al suelo desmayada; todo el conjunto de bellezas llevaron la ilusión a su más alto grado que los espectadores se olvidaron en aquel momento de la actriz, y vieron a Cristina, y sintieron y lloraron con ella [...] (94).

Lamarca se detiene, en especial, en la tragedia Dido. Concepción Rodríguez ha cuidado todos los detalles del personaje; el modo de andar: «firme y majestuoso», que apoya el modelo de suficiencia y superioridad real, que se muestra en: «la natural indiferencia con que se dirigió al trono sin reparar en los personajes que ocupaban el salón» (9I). Hay cierta frialdad en su composición, distanciamiento propio de los que ejercen el poder. A su vez, es capaz de mutar en arrebato pasional y dominar la distinta paleta de emociones cuando la evolución de la tragedia lo requiere:

ora tierna dilata su corazón confiando al seno de una amiga las acervas penas que la afligen, ora rendida suplica a Eneas que no la abandone, ora despechada, deja ver su orgullo por entre las llamas del amor y le recuerda los beneficios que la debe, ora en fin recibe traspasada de dolor la noticia fatal del abandono de su amante; en estos pasos desplegó la Sra. Rodríguez todos los recursos del arte y ayudada de sus grandes facultades, nos presentó a la naturaleza como es en sí (92).

Su réplica en III, 5 (Bretón, I827: 34-40), tras la exposición de Eneas sobre los motivos de su abandono, la resuelve huyendo de la monotonía que caracterizaría, según Lamarca, a un actor mediocre. Concepción Rodríguez muestra estudio, matiz y precisión para cada uno de los mínimos detalles al interpretar las pasiones mixtas: no solo el despecho, sino este junto con el orgullo y la humillación. Actriz, que con una capacidad proteica similar a la de Garrick, domina la transición de las emociones para llegar al momento álgido en el que la protagonista se quita la vida: «En todos los versos que siguen hasta el fin estuvo sublime, y harto manifestaba con el tono patético y profundo de sus acentos que se preparaba a terminar la misma existencia. Se hirió en fin, y en esta escena, la más difícil sin duda, fue acaso también donde brilló más el mérito de la Sra. Rodríguez» (93). Lamarca, sin embargo, detecta una dependencia de la escuela francesa, cierto deje academicista en el recitado de los versos — quizás a esto hacía referencia la «filosófica escuela» a la que según Fontcuberta, como veremos, pertenecía- - le recuerda la necesidad de adaptarse a la versificación española, de seguir el ejemplo de Máiquez y los consejos de Talma, del que transcribe un fragmento de su tratado a propósito del exceso declamatorio francés. Años más tarde, escribirá unos Apuntes sobre el arte de representar destinados a la sección de Declamación del Liceo valenciano, del que era socio. El recuerdo de la interpretación de Concepción Rodríguez se trasladará a este breve tratado (Lamarca, I84I: II), donde invita a los futuros actores a leer la narración de Virgilio sobre la muerte de la reina; ${ }^{\text {Io }}$ solo así se «aprenderá a morir en el teatro. Así moría haciendo la Dido la excelente actriz Doña Concepción Rodríguez» (I84I: 4). La resolución de estas escenas, atenta a un equilibrio entre lo natural y el decoro, aparece explicada en otros tratados de declamación del periodo. Los avisos comparten este resabio de estudio clásico, de tableau vivant, señalado.

Io «Ella los ya cargados ojos baja / Con gran dificultad, mas desfallece. / Tres veces sobre el lecho se incorpora / Apoyada en un codo; y otras tantas / Exánime se abate. A la alta esfera / Vuelve la vista inquieta y perturbada: / Busca la luz, y con hallarla gime» (Lamarca, I84I: 4). 
En ese sentido, el primer manual de declamación aprobado en I834 para los estudiantes del Conservatorio de Música y Declamación precisaba que:

En el último instante es cuando el actor ha de ceñirse a movimientos suaves, como por ejemplo, a dejar caer la cabeza, que más bien indica un hombre acosado de sueño que luchando con la muerte, y a fingir una voz interrumpida, sin detenerse en figurar con demasiada naturalidad los síntomas fastidiosos $u$ horribles de la agonía (Bastús, 2008: 229).

Ese mismo 1834, el abogado Juan Bautista Alonso — futuro Presidente del Consejo de Estado tras la Revolución de la Gloriosa— publicó un poemario que incluye «En loor de la Señora Concepción Rodríguez, primera actriz del teatro del Príncipe, representando el papel de Dido en el quinto acto de la tragedia de este nombre» (1834: 65-69). En efecto, se trata de un extenso poema de dieciséis estrofas que recrean la reacción pasional de la actriz en el desenlace del texto. Convendría rescatar, para el tema que nos ocupa, dos de ellas. De un lado, la estrofa tercera, en la que describe la expresión plástica del dolor a través del cabello, la fisiognómica y la voz de la actriz: «Sin orden el cabello, en tu semblante / Grabada la aflicción y la amargura, / En tus ojos la muerte, en tus acentos / El crimen y el dolor, con ansia fiera. / Desmayas sin aliento / Cabe el trono jinfeliz! que fue tu asiento» (I834: 65). De otro, el momento justo de la muerte de la protagonista (Bretón, 1827: 62), descrito en la estrofa trece, que dice: «Un grito horrendo de furor exalas / Y mostrando un puñal, rauda le escondes / En tu pecho de amor, y moribunda / Y el nombre de tu Eneas pronunciando, / Caes de amor llagada, / Y aun me pareces, muerta, enamorada» (1834: 68).

Un repaso por las actuaciones que programa entre mediados de julio y principios de agosto de 183I en Barcelona atestiguan la fama y madurez de la actriz, el repertorio que domina y la identifica; también el agotador ritmo de trabajo. Entre el I7 de julio y el 2 de agosto protagoniza Dido y la comedia en un acto Las citas - programa para su presentación del I7 de julio-; el 2I, Valeria o La cieguecita de Olbruk junto con la pieza Desconfianza y travesura, ambas traduccciones de Bretón de los Herreros; el 23, la tragedia en cinco actos Gabriela de Vergy, original de Belloy, y el sainete El engaño descubierto, probablemente de Luis Moncín; el 25, habría doble función, en la que interpreta Otelo, Engañar con la verdad, comedia de tres actos traducida por Bretón a partir de Les fausses confidences, de Marivaux y Desconfianza y travesura; el 26 se anuncia como función de despedida Camila y otra traducción de Bretón: El amante prestado, a partir de Scribe y Duveyrier. No obstante, el éxito obliga al teatro a prolongar su estancia. El 28 se presenta con La dama melindrosa, de Lope de Vega — quizás la refundición de Cándido María Trigueros impresa en $\mathrm{I}^{80} 3-\mathrm{y}$ cierra la velada con el sainete Todos embrollados y ninguno con razón; el 30 interpreta Engañar con la verdad y La boda fingida, de Bretón a partir de Destouches. El domingo 3r el teatro ofrece programa doble. A las 4, la actriz protagonizará María Estuarda y Las citas. Al día siguiente, La huérfana de Bruselas y el sainete Los cortejos burlados. Se despide el 2 de agosto con una función de beneficio que empieza a las siete e incluye La Sonámbula, en dos actos; una sinfonía, el quinto acto de Gabriela de Vergy, un baile y la pieza La joven india, nueva traducción de Bretón del original de Chamfort (Diario de Barcelona, I7-VII-I831: 1586; 2I-VII-I83I: I6I8; 23-VII-I83I: I634; 25-VII-I83I: I650; 26-VII-I83I: 1658; 28-VII-I83I: 1674; 30-VII-I83I: 1698; 3I-VII-I83I: I696; I-VIII-I83I: I704 y 2-VIII-I83I: I7I2).

Esta breve incursión en la escena barcelonesa se recordará en otro poemario compuesto por el militar Juan Antonio Suárez y el periodista Joaquín Roca y Cornet. Ambos 
dedican sendas odas a la actriz en las que, de nuevo, recuerdan sus actuaciones en Dido y Camila, en especial su capacidad expresiva y cómo afectaba al espectador: «¿Y es ilusión? ¿Y te cedió natura / Tan celeste poder? ¡Alma hechicera! / ¿Más fuerte conmover nuestra ternura / La verdad consiguiera?» (I831: 22).

De regreso a Madrid, para proseguir con la temporada cómica, interpreta a otra de la grandes protagonistas de Bretón de los Herreros, escrita específicamente para ella: la joven viuda Marcela, en la comedia en tres actos Marcela o i $A$ cuál de los tres? Se estrena el 30 de diciembre de r83 y se programa catorce días hasta finales del enero siguiente. La obra pasa a formar parte de su repertorio habitual. El elenco del estreno lo completaban Rafaela González, José Valero, Carlos Latorre y González Mate, para los tres pretendientes, y el gracioso Antonio Guzmán (Ballesteros Dorado, 2012, I: 667-692). Tanto Bretón como Carnerero reconocieron el buen hacer de todos ellos. El primero, especificaba sobre la protagonista no poderse «representar con más gracia, naturalidad y decoro el carácter de Marcela, huyendo con igual felicidad del orgullo y la coquetería, escollos en que hubiera sido fácil estrellarse una actriz dotada de menos talento escénico» (1965: 172). José María Carnerero, por su parte, destaca varios momentos particulares de su interpretación y reconoce ya la maestría artística que había vaticinado:

Marcela dice su papel con una naturalidad seductora; aquel órgano de voz es precioso: aquellas inflexiones delicadísimas, y muy bien entendidas. ¡Qué bien lee la letrilla a Laura en el segundo acto! ¡Qué sentido da a las décimas con que termina el drama! Hace años califiqué a esta preciosa actriz con el dictamen de Diamante de la escena española. No me he engañado en mi pronóstico (Cartas Españolas, 5-I-I832: 26).

La negativa a que Grimaldi asumiera la empresa, que acabará gestionando el Ayuntamiento, y el desacuerdo entre la actriz con el ajuste que se le ofrece impide su contrata para la temporada de $1832-33$ —en la que nacería su segunda hija Odilia (Gies, I988: I23) - El cantante Agustín Azcona es el designado para negociar los ajustes de los actores. Figurarán, como primeras damas, Antera Baus y Concepción Samaniego. Para completar los primeros puestos del elenco femenino, se contratará a Teresa Baus, como segunda, y se embargará desde Granada, para esta categoría y suplir a las primeras, a la joven Bárbara Lamadrid, primera dama en el teatro de Cádiz, a la que acompañarán su hermana Teodora y su padre, el actor Jerónimo Lamadrid (Ballesteros Dorado, 20I2, I: 699-713; AVM, Corregimento I-80-I2). Bretón de los Herreros reseñará su primera salida que se verifica el I7 de mayo con La huérfana de Bruselas (Diario de Avisos, I7-V-I832: 580; Cartelera, 196r: 22). A juicio del poeta, a pesar de la buena recepción del público, el programa era equivocado. La imagen infantil de Cristina no se adecuaba al físico, al parecer un tanto robusto, de Lamadrid, quien «hubiera podido elegir para su salida otro papel más adecuado a su figura» (Bretón, 1965: 244). Tampoco pasa desaparcibido el que sea un título del repertorio de Concepción Rodríguez, a quien se refiere de forma implícita:

Sabemos que principió su carrera en Sevilla hace muy pocos años al lado de una primera dama, que recientemente lo ha sido en el teatro del Príncipe; sabemos que tuvo la modestia y la buena suerte de ponerse por modelo a una actriz tan justamente celebrada, y el público ha visto que no ha sido vano su estudio ni estéril su aplicación (1965: 244). 
Por eso, la aplaude cuando sigue, para su interpretación de Camila en el mes de julio, a su antecesora, pues:

ha tomado, a nuestro entender, la mejor senda que pudiera haber elegido: imitar $\tan$ escrupulosamente como su buena memoria y muy felices disposiciones se lo han permitido a la grande actriz que fue primera e inspirada intérprete, o, por mejor decir, creadora del papel de Camila, trágico por excelencia (1965: 275).

El propio Bretón da cuenta de la gira que en verano realiza Concepción Rodríguez por provincias, con actuaciones en Sevilla, Cádiz y Granada (1965: 268). Incorpora en varios números de El Correo Literario y Mercantil (23-VII-I832; 30-VII-I832) fragmentos de la prensa sevillana, en la que se destaca el conjunto sublime de su interpretación (1965: 276), o de la gaditana, que se detiene en resaltar su papel protagonista en Gabriela de Vergy, en el que «Cada verso es en ella una belleza, cada transición un rasgo de maestría, cada dificultad un triunfo. Su arte no es el arte que imita, sino que se identifica con la naturaleza misma» (1965: 280-28I). Carnerero recupera el programa de la función de beneficio ofrecida en Cádiz, que incluye La Sonámbula, el acto tercero de Dido, Mi tío el jorobado o Las dos pupilas, los actos segundo y tercero de Otelo y como cierre la comedia en un acto La familia del boticario (Cartas Españolas, carta V, I832: 168). En septiembre, Bretón anuncia su regreso a Madrid (1965: 3II). Grimaldi gestiona con el Ayuntamiento la concesión de la empresa para la temporada de 1833-34, intento que vuelve a frustarse y que trae, entre otras consecuencias, el cierre apresurado de las compañías y el retraso en la llegada de los actores embargados de provincias. Concepción Rodríguez firma su contrata el 26 de marzo de 1833 e inicia así sus últimas temporadas en la escena (AVM, Secretaría 2-474-23; Gies, I988: I00-Io8; Ballesteros Dorado, 20I2, II: I3-23).

\section{El Adiós y el Relevo del diamante de la escena española (i833-i 836)}

La lista de actores para la temporada de 1833-34 se publica el 7 de abril, mismo día en que se inició (Diario de Avisos de Madrid, vII-4-1833: 406-407). Solo se relacionan los artistas de las compañías de verso y de baile, pues no se ha podido completar la de ópera, que no empezará a trabajar hasta junio. La lista recoge los actores que la Comisión de Teatros solicitó embargar el marzo anterior - prerrogativa de los teatros de Madrid desde antiguo y que sancionó la Real orden de 26 de noviembre de 1827 (Cotarelo y Mori, I904: 724-725; AVM, Secretaría 2-475-26)—: Pedro Montaño, de Cádiz; Gabriel Pérez, Juan del Castillo y su hija Carolina, de Valencia; Miguel Ibáñez, de Barcelona, Manuel Casas, de Zaragoza y Nicanor Puchol y Matilde Díez, de Sevilla. No todos firmarían sus contratas. José Manuel de Arjona, Asistente en Sevilla y antiguo Juez Protector de los Teatros del Reino, se resistía a la marcha de los actores solicitados, y consiguió retener a Matilde Díez. Así se lo comunicó el Secretario de Estado y del Despacho del Fomento General del Reino, conde de Ofalia, al Corregidor de Madrid, por Real orden de 30 de abril (AVM, Corregimiento I-79-42). ${ }^{\text {.I }}$

II De este modo, el elenco de la compañía de verso quedó configurado por las siguientes actrices: Antera Baus y Concepción Rodríguez — como primeras damas—; Catalina Bravo y Bárbara Lamadrid — como sobresalientes —; Teresa Baus, Joaquina Baus y Carolina del Castillo — como segundas —; Rafael González, Felisa Rodríguez y Ramona León — para el carácter jocoso —; María Cabo, Mariana Castillo y Manuela Palomino — para cuartas y quintas damas - J Jerónima Llorente, Dolores Pinto y Casimira Delgado — como características-; María Fabiani, María Martínez, Teodora Lamadrid, Josefa Valero y Juana Máiquez — como supernumerarias- Con respecto al elenco masculino: José García Luna y Carlos Latorre, se contratan como primeros galanes; Pedro Montaño y Nicanor Puchol, comparten también esta categoría. Les siguen: Antonio Silvostri, Ramón López, José Tamayo, Pedro 
Concepción Rodríguez firma el convenio de ajuste con la Comisión de Teatros el 26 de marzo, como ya indicamos. Contiene las nueve condiciones comunes a otros contratos - con las particularidades correspondientes a su categoría-, y añade cuatro cláusulas extraordinarias, algunas de las cuales aparecen también en los de los colegas de similar jerarquía para esa o próximas temporadas (AVM, Secretaría 2-474-23; 2-473-80; 2-47422; Ballesteros Dorados, 2012, I: 707-708). Se contrata para un año cómico en clase de primera dama con remuneración de 30000 reales — condiciones $\mathrm{I}^{\mathrm{a}}$ y $5^{\mathrm{a}}$ —; debía aceptar el papel que se le asignase desde la Comisión en cualquier tipo de pieza, incluidas los sainetes $-2^{\text {a }}$-; el vestuario de trajes comunes correría de su cargo $-3^{a}$-; se señala la sanción por no concurrir o llegar tarde a los ensayos - $4^{\text {a }}$; los días en los que no se remuneraría su trabajo por no haber función - $6^{\text {a }}$; los motivos por los que se suspendía la contrata — por ejemplo, por fallecimiento de determinados miembros de la familia real — y la indemnización a percibir $-7^{\mathrm{a}}$-; así como el sistema jurídico por el que se regía su cumplimiento $-8^{\circ}$ y $9^{\circ}$ - . Los cuatro acuerdos que añadía se referían: por un lado, a una gratificación de 5000 reales, a modo de incentivo "por lo cual se obliga también a contribuir por su parte al mayor esmero y actividad en el trabajo en beneficio de los fondos municipales»; por otro, disfrutaría de cuarenta días de licencia. Además, firmaba que si los teatros pasaban a empresario particular podría rescindir el contrato o bien renegociarlo. Por último, y en caso de que se rescindiera, se liquidaría la cantidad adelantada salvo la correspondiente al periodo trabajado (AVM, Secretaría 2-474-23).

Su primera aparición se verifica el I2 de abril con Gabriela de Vergy, función que repite el I3 y el I4 (Cartelera, I96r: 28; AVM, Secretaría 6-3II-3). Larra, que señala deficiencias en el desarrollo dramatúrgico de la acción, sobre todo en el acto quinto, elogia el que las resuelva al dosificar las reacciones emocionales. No se trata de una actriz previsible que se deja arrastrar por el grito fácil, sino de una actriz de categoría, que soluciona con su buen hacer momentos controvertidos de un texto, y que estudia con precisión los golpes de efecto (La Revista Española, I6-IV-I833: 497-498). La reseña de Bretón de los Herreros, publicada el día anterior en El Correo Literario y Mercantil, si bien elogia la interpretación de su pareja escénica, Carlos Latorre, se centra en la actuación de la actriz. Saluda entusiasmado su regreso a la escena madrileña:

El anuncio de esta función lo era también de una entrada considerable atendiendo el género a que pertenece, y el poderoso incentivo que debía ser para los amantes del teatro español la presencia de una actriz tan distinguida después de haber sentido su ausencia por espacio de un año. Fue pues crecida la concurrencia; y la Sra. Rodriguez, muy lejos de desmentir en lo más mínimo el concepto de consumada actriz que tenía adquirido, superó en más de un lugar las esperanzas del público (1965: 405).

Mate, Antonio Rubio, José Alcázar y Gabriel Pérez. Los actores que desempeñan los papeles de anciano son: Elías Norén y José Galindo — como primeros- y Juan Antonio Campos, Luis Fabiani y Pedro López. También figuran contratados Bruno Rodríguez, Santos Díez y Emilio Alverá. Los actores de carácter jocoso serían: Pedro Cubas y Antonio Guzmán. Figuran como sobresalientes: Agustín Azcona, Juan del Castillo, José Guzmán, Ignacio Silvostri y Guillermo Fernández. La lista la completan los siguientes racionistas: Antonia Mas, Carmen Concha, María Caset, Juliana Torres, Felisa Valero, Saturnina Velasco, Dolores Pérez, Rosa Gómez, Joaquín Lledó, Mariano Casanova, Manuel Morales, Miguel Gómez, Pedro Antonio Lobo, Sebastián Espinosa, José López y Juan Alonso. El i8 de abril se contrató a Julián Romea, previa autorización del Conservatorio en el que estaba formándose para «ejecutar todos aquellos papeles para que se le crea úitil y los demás adecuados a su carácter y figura». Se le asignaron 24 reales (AVM, Secretaría 2-474-18; Secretaría 2-474-22; MNT, Doc. 3452). 
La intérprete que domina, lo venimos viendo gracias a las críticas anteriores, los recursos de lo sentimental, destaca por evitar la monotonía de su recitado, por su variada expresividad en la pintura de las emociones y, de nuevo, por la resolución del final que cierra con su muerte:

Y cuando en el quinto acto llega al colmo su infortunio cuando en vez del ansiado veneno descubren sus ojos el atroz e inesperado suplicio a que la condena Fayel, cuando estos ojos buscan acerbas lágrimas en vano:

cuando su amargura se convierte en despecho y furor, y sus dolientes ayes en espantoso delirio, ¿qué expresiones bastan a hacer dignamente su elogio? ¿Quién oye sus gritos sin estremecerse? ¿Quién escucha sus imprecaciones sin lástima y sin terror? ¿Quién ve pintadas en su rostro las angustias de la muerte sin maldecir a sus verdugos?... No concebimos que quepa en el teatro más sublime, más perfecta imitación de la naturaleza (1965: 406-407).

$\mathrm{Su}$ exitoso regreso se empaña por un desagradable episodio en torno al sainete $E l$ joven de sesenta años, versión de Bretón a partir de la que Félix Enciso Castrillón realizó de Le Ci-devant jeune homme, de Merle y Brazier, en cuyo estreno, el 27 de agosto de I815, partició Isidoro Máiquez. La pieza se vio el 29 de octubre de 1827 y se mantuvo hasta el 3 de noviembre con Agustina Torres, en el papel de la joven viuda Clara, y Antonio Guzmán, en el del viejo don Pedro, verdadero protagonista del texto. Santiago Casanova interpretó al joven Carlos. Se reprogramó, por su buena acogida, en años posteriores —enero de 1828, octubre de 1830- con alguna modificación en el elenco. El Corregidor, Domingo María de Barrafón, había dictado que se representase para el 3 de mayo de 1833 . La Comisión de Teatros encargó a Antonio Guzmán, primer gracioso, que confeccionara el reparto, pues a él le correspondía, por convenio: «dirigir las piezas en que haga el protagonista y en las demás que le encargue la Comisión con la facultad de Director» (AVM, Secretaría 2-474-22). Asignó el del joven Carlos a Latorre y el de Clara a Concepción Rodríguez, quienes los rechazaron por entenderlos inferiores a su categoría, tal y como consta en el jugoso expediente que se conserva sobre el asunto (AVM, Secretaría 2-475$45)^{\mathrm{r2}}$ y del que ya ha dado cuenta Ballesteros Dorado (2012, I: 325-344). La actriz abofeteó al representante de la Comisión, Cristóbal Cuesta, e insultó a otros miembros presentes en la contaduría del teatro. El griterío se escuchaba desde el escenario donde se daba función: «escandalizando de tal manera, que con motivo de estarse en la representación hubo que cerrar las puertas de dicha Contaduría pues subieron algunas personas que oyeron las voces que daba, las que también [oyeron] los mismos Señores que estaban en el Palco del Ayuntamiento» (AVM, Secretaría 2-475-45). La Comisión, que se sentía «vilipendiada por una Cómica», recurrió al Corregidor para que mediara. A él se dirigió, por su parte, la actriz en una extensa exposición firmada el 30 de abril en la que conviene detenerse. En ella aclaraba que devolvió el papel por considerar que hubo confusión o malas intenciones al entregárselo. Apelaba a que en los quince años de carrera en los teatros de Madrid nunca se había dejado en entredicho su buen nombre. Afirmaba, además, que, a pesar de aborrecer la carrera artística — como repetirá un par de años más tarde a propósito de su función de beneficio—, se había conducido siempre de modo ejemplar:

I2 En la minuta del documento evacuado por la Comisión de Teatros en 29 de abril aparecen tachadas las abreviaturas Sr. y Sra. delante de los apellidos de Latorre y Rodríguez (AVM , Secretaría 4-475-45). 
Ella nunca se envaneció con aplausos harto estériles en el deplorable estado de nuestra Escena, pero sí lo hará en esta ocasión con la conducta sin mancha y el incansable celo y docilidad que tan esencialmente la distinguieron siempre en la más que nunca aborrecida carrera que se ve precisada a seguir. ¿Habría de desmentir en un día la opinión adquirida en todos tiempos y bajo todos los sistemas que han regido o arruinado los teatros de la Corte de i5 años a esta parte?

La actriz justificaba su rechado a partir de los siguientes argumentos: en primer lugar, por la baja calidad general de determinadas obras cómicas. Se trataba de un sainete, pieza de entretenimiento vulgar: «sainete es en el original francés, pues se escribió para los farsantes encargados de divertir en tablas subalternas al populacho de París; sainete es en la traducción española, pues sainete llaman los españoles cualquier composición jocosa en un acto corto, de frívolo argumento». En segundo lugar, a que no correspondía a los primeros galanes y primeras damas participar en estas piezas: "por juzgarse tan innecesario como indecorosa su participación»; para ello ya estaban los segundos galanes, la tercera dama — tradicionalmente la graciosa - o los ajustados en la categoría de sobresaliente. Y, en tercer lugar, por el poco lucimiento que le ofrecía ese papel en concreto - pues piezas cómicas y en un acto, como hemos visto, formaban parte de su repertorio-:

porque de ninguna manera puede verse en él papel de $\mathrm{I}^{\mathrm{a}}$ Dama. El papel tiene tres hojas escasas, en todo él no hay que decir de seguido arriba de 4 a cinco palabras, ninguna suerte de pasión o afecto se deslinda de él, y seguramente no se juzgará necesario el auxilio de la $\mathrm{I}^{\mathrm{a}}$ actriz en un papel donde basta y sobra la más parca actitud de la última.

Edición en mano, Concepción Rodríguez tenía su parte de razón. Más allá de lo insustancial del papel -y del dicho común entre la profesión a propósito de que no hay papeles pequeños sino grandes actores-, de un total de dieciocho escenas de la obra, Clara aparece en tres: en la doce y en las dos últimas. Suma en total treinta y seis réplicas. Solo una, con trece, supera los seis versos. ${ }^{13}$ En fin, El joven de sesenta años está compuesto, quizás nunca pretendió otra cosa, para mayor gloria del primer gracioso. Y a él se refiere también la actriz en la exposición, pues denuncia que en los últimos años Guzmán ha usurpado funciones propias de las primeras figuras serias. Lo que interesa aquí es la asunción de una conciencia de actriz y del rol que debían desempeñar los distintos actores dentro de la compañía. ${ }^{\mathrm{I4}}$ La primera dama, herida en su orgullo artístico, solicitaba no desempeñar el papel o elevar la cuestión a «peritos facultativos como lo son los 4 maestros efectivos u honorarios de la clase de declamación en el Real Conservatorio de María Cristina». Este último detalle no deja de ser curioso - como notó la Comisión de Teatros que tuvo que pronunciarse sobre el memorial - ya que uno de los maestros de la Escuela de Declamación, impartía Literatura castellana, era Enciso Castrillón, el traductor original de la pieza. Tampoco era una sugerencia inocente pues la cátedra de Declamación la desempeñaban entonces Joaquín Caprara y Carlos Latorre, con quien habitualmente compartía las parejas protagonistas y que, como ella, había rechazado, en un principio,

I3 Sigo la traducción de Enciso Castrillón (1815). El papel de Clara, en la versión de Bretón de los Herreros, no debió diferir en exceso, si atendemos a las variantes de los manuscritos conservados en la Biblioteca Histórica que ha estudiado Ballesteros Dorado (20I2, I: 325-33I).

I4 Por lo demás, parece que la relación profesional entre la primera dama y el primer gracioso conoció otros momentos tensos fruto del ego artístico (Ballesteros Dorado, 20I2, I: 338; II: 47). 
el reparto asignado. No se consultó a ninguno de ellos, ni tampoco a Andrés Prieto ni a José García Luna - a los que conococía bien-; maestros honorarios de Declamación del Conservatorio (Soria Tomás, 2010: 296-317 y 341-344). Finalmente, Barrafón, atendiendo a lo prescrito en las contratas, obligó a la actriz a representar la obra. Esta pretextó estar enferma, lo que obligó a reprogramar la tragedia Zeidar, de Ducis en traducción de Villanuea y Ochoa, que protagonizaba desde el 5 de mayo, por otras funciones. La actriz, castigada con el pago de una multa de veinticinco ducados y la amenaza de terminar en la cárcel, interpretó El joven de sesenta años el I3 y I4 de mayo (AVM, Corregimiento I-7826; Secretaría 2-475-45; 6-3II-3, Ballesteros Dorado, 20I2, I: 344 y II: 23).

A lo largo del resto del año cómico, en el que se cerraron temporalmente los teatros, primero por la epidemia de cólera y luego, del I de octubre al I de diciembre, por el fallecimiento de Fernando VII, actúa, previsiblemente, en los siguientes montajes: El marido en picos pardos, Edipo, Lo que son mujeres, todas en 5 actos; Contigo pan y cebolla, La nieve, las tragedias Óscar y Pelayo, en cuatro; La dama duende, Lisonja a todos, La presumida y la hermosa, en 3; La Sonámbula y La Julia, en 2; y en las piezas en un acto: El músico y el poeta, Las esposas vengadas, La loca fingida y en El triunfo de la inocencia, loa compuesta por Bretón de los Herreros y programada en junio con motivo de la Jura de la princesa Isabel (Ballesteros Dorado, 20I2, II: 6I-78; AVM, Secretaría 6-3II-3). Quizás convendría destacar de todos ellos el estreno de la comedia de Eduardo de Gorostiza, Contigo pan y cebolla, que se verifica el 6 de julio en el Teatro del Príncipe y se mantiene los días 7, 8, 9, I2, I3 y I4 (Cartelera, I96r: 30). Tanto Bretón como Larra centraron parte de sus críticas en las virtudes y defectos de la construcción dramática, en particular en lo exagerado y poco verosímil del carácter de Matilde (La Revista Española, 9-VII-I833: 70I-702; Bretón, I965: 443-447), que se resuelve gracias a la pericia de Concepción Rodríguez. Para Bretón habría

pintado con maestría un carácter anfibio entre la ternura y la extravagancia, creación de una cabeza románticamente evaporada y de corazón sencillo y afectuoso; o, si queremos darle otro origen, creación defectuosa del poeta mejorada por una actriz que también sabe crear cuando parece que se ciñe a una servil imitación: tales son y tan obedientes sus inspiraciones los varios resortes de su voz y de su fisonomía (I965: 442-443).

Durante la siguiente temporada, Carlos Rebollo consigue, por un periodo de cinco años, la empresa, pero es Grimaldi quien ejerce de representante y director, con las oportunas consecuencias en el cuadro artístico. No se contrata a Agustín Azcona, responsable, en parte, de las de la temporada de 1832-33 que dejaron fuera a Concepción Rodríguez. Azcona arremeterá desde el Semanario Teatral contra la empresa y la actriz (Ballesteros Dorado, 20I2, II: II7-I30; La Revista Española, 25-III-I834: 3I2). Se incorporan, entre otros, Miguel Ibáñez, desde Barcelona, y Matilde Díez, desde Sevilla. Al parecer Grimaldi la habría visto representar ahí en la temporada de 1830-3I, aunque otras fuentes hablan de la intermediación de García Luna. ${ }^{15}$ Se ajusta, por la posición en que figura en las listas, como segunda dama joven, si bien, en seguida, desempeñará la de primera. Público y prensa la reciben con entusiasmo. Tanto la programación como las críticas aventuran una

I5 Roca de Togores (1883: 70). Sobre sus actuaciones antes de venir a Madrid ver Blasco (I880: 249-25I). Su padre José Díez, nacido en Madrid en torno a I783, fue actor especializado en los papeles de barba que trabajó tanto en provincias como en la capital. Falleció en I85r. Su hermano, que se llamaba igual que su progenitor, también ejerció la profesión cómica. Llegó a ser segundo galán y se retiró de la escena en I855 (MNT, Doc 3452; AVM, Secretaría 4-16I-51 y 6-I87-58). 
suerte de relevo entre las actrices. A la mayor atención que esta recibe se suman pequeños defectos en el trabajo de Concepción Rodríguez en reseñas que le dedican, con alguna excepción, menos espacio, a pesar de que en mayo protagoniza el gran éxito de la temporada: La conjuración de Venecia, de Martínez de la Rosa. La nueva dama joven debuta en Madrid con varios textos que constituían el repertorio de Concepción Rodríguez: el 7 y el 8 de abril protagoniza La huérfana de Bruselas y el sainete Los tres huéspedes burlados. Tras actuar en El testamento y El amante perdido, el día in interpreta a La niña en casa, de Martínez de la Rosa. La crítica de El Universal, es probable que de Bretón, se pronuncia positivamente sobre su estreno. Destaca su menuda constitución-tenía entonces I6 años- y su voz, que paracen destinarla a una categoría particular de papeles, alejados de la tragedia —su dilatada carrera lo desmentirá-:

$\mathrm{Su}$ acento tiene una dulzura que encanta, y es de aquellos que hallan fácilmente el camino del corazón; así es que desde las primeras palabras que articula se capta la benevolencia del espectador. Su agraciado rostro se presta sin violencia a la pintura de tiernos sentimientos. El papel de protagonista en el drama titulado La buérfana de Bruselas conviene perfectamente a sus facultades. Creemos que mientras las conserve podría siempre representar con aceptación jóvenes modestas, inocentes, amorosas, ingenuas. Para papeles más fuertes, para aquellos que brillan por la energía y la vehemencia de las pasiones, quizá no fuera tan a propósito, aunque la poquedad de su estatura no la excluyera de ejecutar algunos, al paso que para otros poco puede perjudicarla siendo como es bastante bien formada. En una palabra, la señora Díez es excelente para dama joven: y como al mismo tiempo tiene viveza y anuncia ingenio no vulgar, nos parece que también podrá ser útil para papeles de criaditas sagaces, revoltosillas y emprendedoras (9-IV-I834: I).

Larra, que coincide en las apreciaciones sobre su físico, alaba otras cualidades — su accionado, su voz - y la insta a no dejarse seducir por los primeros aplausos recibidos. Recuerda, con justicia, lo que se le debe del papel a la primera dama, que aparece aquí como modelo:

La figura de la Señora Díez por desgracia no es imponente, pero su gesticulación agradable y fácil, y su acento sobre todo en gran manera grato y penetrante se sobreponen, al punto que habla, a la primera impresión y aun la borran completamente. El papel de La huérfana de Bruselas no es ciertamente papel de principiante y fuerza es tener mucho mérito para arrancar en él los aplausos de entusiasmo que arrancó la Sra. Díez a un público que le ha visto hacer tantas veces a la Sra. C. Rodríguez. Conócese que esta ha servido en alguna parte de modelo a la nueva dama: pero échase también de ver sobradamente que quien sabe tomar el ejemplo sin imitación servil ni trivial remedo, quien con tanta naturalidad sabe hacer propia una creación ajena, es capaz de crear por sí [...] (La Revista Española, 9-IV-I834: 349).

A la semana siguiente, reseña su interpretación en La niña en casa y la madre en la máscara, antiguo éxito de Concepción Rodríguez. El periodista destaca cualidades comunes con esta última: sensibilidad, inteligencia, $y$, a su vez, le aconseja matizar algunas reacciones: 
¡Qué ternura! ¡Qué inteligencia! ¡Qué voz! Solo quisiéramos que en las escenas que tiene con personas para ella indiferentes, afectase menos recuerdos de su amante. Mientras más disimulo tuviese en ausencia de Teodoro, más resaltaría su pasión en presencia de este: hay cierta sequedad en sus respuestas al tío y a don Luis en los primeros actos llevada algún tanto al extremo (La Revista Española, I4-IV-I834: 367).

Por su parte, la primera dama del Teatro del Príncipe había iniciado la temporada el 30 de marzo con Un novio para la niña o La casa de huéspedes, comedia en tres actos original de Bretón, por la que si bien recibió los elogios del dramaturgo — «pintó el amor, la inocencia, la timidez de una manera que no se ve sino cuando ella lo hace; y en la citada escena sexta del segundo acto dijo aquellas palabras de indignación de una manera que no se oye sino cuando ella lo dice» (El Universal, 2-IV-I834: 2) - Larra consideró de poco lucimiento: «solo diremos que el papelito de que estaba encargada debía de ser para una actriz de su mérito prueba bien subalterna. Alabarla en él sería suponer que podía no haberlo desempeñado. Para cosas de más empeño le reservamos nuestra crítica» ( $\mathrm{La}$ Revista Española, I-IV.I834: 320 ). Los días 5 y 6 de abril interpreta Gabriela de Vergy, pieza de su repertorio. $\mathrm{El} 23$ estrena el gran éxito de la temporada, y uno de los primeros dramas románticos que protagonizará, La conjuración de Venecia, de Martínez de la Rosa, que se

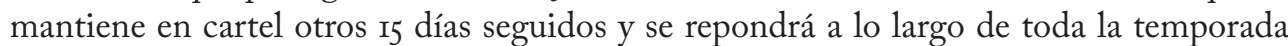
(Rubio, I99I: I53-I56). ${ }^{16}$ El Correo de las Damas (25-IV-I834: 7-8) y el Semanario Teatral (28IV-I834: 7) aprueban la labor del elenco. La crítica de Larra - muy elogiosa con el texto y todo el aparato escénico de la dirección- es más explícita con respecto al trabajo de Concepción Rodríguez, quien:

ha interpretado con perfección su papel; esa es la Laura sensible, amable, que ha pintado el poeta. ¡Qué calor y qué verdad en aquellas palabras: «Es mi esposo a los ojos de Dios y yo debo salvarle a costa de mi vida... ¿Qué me importa lo que digan los hombres?». Es difícil imaginar mejor la escena con Rugiero y con el padre, imposible confundir y mezclar mejor en uno los sentimientos de amor y de pavor de su salida en el panteón. Tributamos con gusto estos elogios justísimos a esta distinguida actriz (La Revista Española, 25-IV-I834: 407).

El 24 de mayo repone, en el Teatro del Príncipe, El colegio de Tonnington o La educanda. Alrededor de estas fechas José Escobar contextualiza la publicidad del conflicto entre partidarios de la nueva empresa y dirección teatral — Grimaldi, Larra, Bretón y Ventura de la Vega- y sus detractores, encabezados, entre otros, por el cantante Agustín Azcona, quien se sirve de las páginas del Semanario Teatral para lanzar sus críticas (I976: 45-72). Concepción Rodríguez, cuya actuación Larra resuelve con un taxativo «ha sido perfecta» (Larra, 2010: 370), ${ }^{17}$ no sale airosa de las páginas de la prensa rival que indica que: «la señora Rodríguez no está ya en el caso de hacer las niñas» (Escobar, I976: 67). Azcona añadió que Matilde Díez era más a propósito para esos papeles. ${ }^{18}$ Acierta

I6 No lo estrenó Concepción Samaniego, a la sazón otra de las primeras damas del teatro de este periodo. En I853 solicitó licencia para contratarse en los teatros de La Habana (Ribao, I999: 47; MNT, Doc. 3452; AVM, Secretaría 4-104-46).

I7 La crítica se ha sustraído del ejemplar de La Revista Española (27-V-I834) disponible en la Hemeroteca Digital de la BNE.

I8 Parece que solo se conserva un ejemplar del no 7 del Semanario Teatral donde se incluye esta crítica, correspondiente al 2 de junio de 1834 (Escobar, I976: 57). Está custodiado en la Fisher Library de Toronto. No me ha sido posible acceder a él, a pesar de las gestiones realizadas, por encontrarse temporalmente cerrada. Remito pues a la 
Ballesteros Dorado cuando puntualiza que «más de treinta años en una mujer de la época la situaban en la "mediana edad"» (20I2, II: 155; Rabaté, 2007: passim). En cualquier caso, la pieza debió de tener buena acogida pues se mantuvo durante seis días y se repuso en 1835 , aunque en el Teatro de la Cruz y con Matilde Díez en el papel femenino protagonista. Fue, de hecho, el título que escogió para inaugurar su contrata en la temporada de 1836-37 en el Teatro de Barcelona (El Vapor, 26-IV-I836: 4).

Quizás la dirección de los de Madrid pensó en dejar de asignar determinados papeles de dama joven a Concepción Rodríguez para reservarle los de las tragedias. Así, por ejemplo, en la reposición de El casamiento por convicción o La fuerza de la razón - traducción de Bretón a partir de Scribe y Varner, que desempeñó en julio de i828- vista en el Teatro del Príncipe el in de agosto, interpretaría, ahora, el papel de la graciosa Paca, esposa de Pinto, el labrador; Matilde Díez, el de la joven Susana. Larra supo resaltar lo positivo de cada una de ellas (La Revista Española, I2-VIII-1834: 804 ). Se trata, a nuestro juicio, de una crítica contemporizadora, pues mientras afirma que la empresa podía aprovechar mejor las cualidades de la nueva primera dama, reconoce la superioridad de Concepción Rodríguez, en virtud de su veteranía y trayectoria. No en vano, Grimaldi estaba preparando el montaje de Macías, que se estrenaría el 24 de septiembre, con Concepción Rodríguez en el papel de Elvira; nueva heroína que termina quitándose la vida y de cuya interpretación la crítica reconvino el que precipitara determinados pasajes (Eco del Comercio, 26-IX-I834: I-2). Encarnaría a otras damas románticas, como a Leonor en Don Álvaro o La fuera del sino, del duque de Rivas, estrenada el 22 de marzo de 1835 a punto de concluir la temporada (Andioc, 1982: 63-86; Ribao, 1999: 57-71; Caldera, 200r: 69-84). La crítica destacó tanto su actuación como la de Matilde Díez en la gitana Preciosilla. Distintas recopilaciones de semblanzas de actores y anecdotarios escénicos insisten en que Grimaldi afirmaba, a partir de esta interpretación, que Matilde Díez sería la actriz que «eclipsaría» a Concepción Rodríguez (Sepúlveda, i888: 305-306; Reyes, 1977: 57). El mismo día del estreno, se nombró a Concepción Rodríguez Maestra honoraria de declamación. La Real orden trasladada desde el Ministerio de lo Interior al Conservatorio reza como sigue:

He dado cuenta a SM la Reina Gobernadora de una exposición de Concepción Rodríguez actriz de los teatros de esta Corte en solicitud de que se le conceda el título de Maestra honoraria del Real Conservatorio de Música, y SM atendiendo a sus servicios y circunstancias de la interesada se ha dignado concederle la gracia que pide (ARCSMM, Leg. 2-I4O).

No hemos localizado la petición de la actriz —al menos no se conserva ni en los fondos del ARCSMM ni en los del AGA, que custodian los expedientes de los maestros vinculados con el Conservatorio- Fue la primera mujer en conseguir esta distinción. El reconocimiento no llevaba, al menos durante la primera etapa del centro, aparejada docencia alguna, pero le permitiría vestir con el uniforme al efecto y, en cualquier caso, la distinguía entre las dedicadas a su arte; pues ese era el objetivo último de esta figura (ARCSMM, Leg. 3-48; Soria Tomás, 2010: 383). Consiguió, igual que los catedráticos José García Luna y Carlos Latorre, poder emplear el tratamiento, en su caso, de Doña; tal y como recogió la prensa. Sobre lo oportuo de esta consideración se pronunció La Revista Española (29-III-I835: I2I-I22) que solicitaba se hiciera extensible a todos los actores, no

reproducción parcial de Escobar y al fragmento traducido por Gies (I988: Irg). 
solo a los vinculados al Conservatorio. La Abeja insertaba el anuncio de la real orden y añadía la siguiente aclaración:

El público, justo admirador del talento sobresaliente de una actriz que es la gloria de la escena española, recibirá sin duda con placer esta noticia. Por nuestra parte no podemos menos de celebrar que SM la Reina Gobernadora haya empleado tan dignamente la primera gracia de esta naturaleza que hasta ahora se ha dispensado a actrices españolas; y si la señora doña Concepción Rodríguez se hallaba en efecto disgustada de su profesión, no porque en el ejercicio de ella haya dejado aceptación, sino por otros motivos que no tratamos de indagar, nos alegramos sobremanera de que alentada con un rasgo de real benevolencia, por todos conceptos merecido, continúe ciñendo laureles a su frente en los teatros de esta corte, a cuyo esplendor tanto ha contribuido (28-III-I835: 2).

Vimos más arriba, a propósito del bofetón de El joven de sesenta años, que la actriz consideraba negativamente la actuación. Cierto malestar parece también inferirse de estas líneas de La Abeja. Quizás los «otros motivos que no tratamos de indagar» estén relacionados con el desenlace de la función de beneficio que protagonizó un par de meses antes, y que la obligaron a salir de Madrid por no terminar encarcelada, como pasó con el empresario Carlos Rebollo.

El programa para su beneficio, puesto la noche del 3I de enero en el Teatro del Príncipe, lo formaron: el drama en cinco actos Fenelón o Las religiosas de Cambray, que contaba con el aliciente de recuperar a Joaquín Caprara, retirado de la escena y dedicado a su magisterio en el Conservatorio; un intermedio musical, una nueva traducción de Ventura de la Vega: la comedia en un acto El presupuesto, bailes nacionales y el sainete La gila y el sacristán con participación de Guzmán. A la función asistió la Reina Gobernadora y una numerosa concurrencia, que ya anunciaba la dificultad de conseguir entradas. Estas terminaron vendiéndose no en la taquilla, como de ordinario, sino a través de la contaduría o directamente se entregaron en casas particulares vía esquelas. Al descontento que generó la poca transparencia sobre la entradas se sumó la dudosa calidad de El presupuesto. Ante la reacción airada del público, Carlos Latorre bajó el telón y se interrumpió el programa. La prensa dio cuenta del desastroso resultado. El Mensajero de las Cortes, por ejemplo, afirmaba que «la pieza cayó por disparatada, por descabellada, por fría, por tonta; pero de tal género de tontuna que era imposible que la aguantara un público que no fuera de piedra, por acostumbrado a que esté a aguantar transpirenaicos desatinos vertidos en galaico-castellano» (2-II-I835:4). Otras cabeceras se pronunciaron en la misma línea (Correo de las Damas, 7-II-1835: 35-36; La Revista Española, 2-II-I835: 1505). Para Bretón, desde La Abeja, ni siquiera la pieza principal hacía justicia a Concepción Rodríguez: «El papel que en este drama representaba la beneficiada es harto plañidero y acomellado, si se nos permite la expresión, para que pueda brillar en él» (3-II-I835: I-2). Así pues lo que debería haber sido un baño de reconocimiento concluyó en pública humillación a la que se unió la multa a los distintos implicados: 20 ducados a Carlos Latorre por bajar el telón sin consentimiento de la autoridad competente; al empresario y a la actriz a 5 , por el sistema fraudulento seguido con las entradas, al que se sumaron otros 20 por no abonar la cantidad cuando se requirió. El Corregidor, el marqués de Pontejos, ordenó a Rebollo el pago de la multa y que anunciara mediante una tablilla la relación de billetes disponibles para las funciones. Este se negó e ingresó en la cárcel el 4 de febrero. La actriz movilizó a su círculo de influencia y consiguió que Martínez de la Rosa, entonces Presidente del Consejo de Ministros, mediara para que se revocara la multa. El ro de febrero 
el Presidente se dirigía así al Corregidor: «Mi estimado amigo: remito a V la solicitud de la Concepción para que se muestre usted generoso, como me ofreció, perdonándole la multa: al fin es Dama» (AVM, Corregimiento I-I86-65; Ballesteros Dorado, 20I2, II: 199-203). El marqués de Pontejos levantó la de 50 ducados, pero mantuvo la de 20, pues suprimirla «ahora con la publicidad que ya tiene este asunto se atribuiría a debilidad o contemplación». La actriz insistió en un segundo memorial — que no fue atendido en su totalidad, pues terminó sufragando las costas- enviado al Corregidor el i6 de febrero (AVM, Corregimiento I-I86-65). Ahí expone que se marchó de Madrid por miedo a terminar encerrada. Aprovechó para dirigir a la Reina

una respetuosa súplica en la que, confesándole desde luego la especie de desobediencia cometida, le imploraba de la Angelical de SM el perdón que pudiese necesitar al paso dado por la suplicante. Díjosele posteriormente que SM se había dignado conceder el solicitado perdón, y bajo tan poderosa salvaguardia volvió a Madrid el domingo 7 a cumplir con la odiosa contrata teatral que la sujeta por algún tiempo todavía. La engañaron sin duda los que así se lo aseguraron, puesto que VS persiste en la imposición de los veinte ducados de multa.

Tranquilizaba al Corregidor sobre su conducta. No habría insubordinación ni el perdón de la deuda traería consecuencias negativas pues estaba resuelta a dejar la escena:

Poco le ha de costar vivir subordinada, pues se aproxima el término de sus obligaciones. Renuncia al expirar su actual contrata, renuncia al ejercicio de un arte ingrato, en cuya cultura ni los vanos laureles adquiridos, ni la práctica de las virtudes privadas, bastan a sustraerla a ciertas humillaciones que desgraciadamente conoció tarde, y a que no la tenían por cierto preparada ni su educación ni sus demás circunstancias personales; sea dicho esto sin la menor ofensa de VS en particular, y sí solo en alusión al infeliz y degradante estado del pobre teatro nacional. ${ }^{19}$

De hecho, la prensa, que desgrana posibles ajustes desde principios de marzo, especula con su posible retiro. Lo hace, entre otros, Bretón, en el boletín de La Abeja. «Novedades teatrales» (2-III-I835: I). Su nombre no figura en una primera relación de actores que ofreció La Revista Española el mismo día en que firmaba su solicitud para el perdón de la multa (I6-II-I835: 1564). El ajuste debió cerrarse en días posteriores (La Abeja, 7-IIII835: I; La Revista Española, 8-III-I835: 32; Eco del Comercio 22-III-I835: 2). La principales actrices que, finalmente, constituyeron la compañía de declamación fueron Concepción Rodríguez, Bárbara Lamadrid, Matilde Díez - ya con categoría oficial de primera dama-, Teresa Baus y Patrocinio Infantes. El elenco principal masculino lo formaban: José García Luna, Carlos Latorre y Julián Romea (AVM, Secretaría 4-16r-5; MNT, Doc. 3452; Revista española, I9-IV-I835: 208; La Abeja, 20-IV-I835: 4; Ballesteros Dorado, 20I2, II: 200-203). ${ }^{20}$ Es probable que el nombramiento de Maestra honoraria fuera una manera

I9 Estas afirmaciones podrían ser retóricas y destinadas a obtener un mayor beneficio, como señaló Peláez a propósito de una exposición presentada por María Ladvenant en el año cómico de 1765-66 en la que afirmaba querer retirarse (2000: 150). Existen, por otro lado, varios patrones para el abandono de la escena por parte de las grandes actrices, bien por enfermedad o jubilación, por contraer matrimonio y dedicarse al cuidado del hogar, bien por arrepentimiento o por alguna forma de conversión que las lleva a ingresar en un convento (Martin-Fugier, 2008: 279-292).

20 El resto del elenco femenino lo componían: Isabel Boldún, María Fabiani, Ramona León, Francisca Casanova, Mariana Castillo, María Martínez, Gerónima Llorente - en la categoría de características que desempeñaba anteriormente Concepción Velasco - Catalina Illot, Teodora Lamadrid, Concepción Lapuerta, Ramona Fournier, María Córdoba, Antonia Mas, Antonia Monreal y María Josefa Fresno. 
de resarcirla del desaire anterior. También contribuiría la publicación de la semblanza de Grimaldi, próxima en el tiempo.

En esta temporada, estrena las dos primeras adaptaciones de Víctor Hugo, que contribuyeron a la incorporación, no exenta de debate, del drama romántico francés a la escena española: Lucrecia Borgia y Ángelo; ambas programadas en el Teatro del Príncipe. La primera, drama en cinco actos en traducción de Pedro Ángel de Gorostiza y Cepeda (Saura Sánchez, 2007: 100-102), se estrenó el I8 de julio de I835 y se programó en trece ocasiones a lo largo del año. La recepción crítica fue dispar y un sector de la prensa tendió a señalar su inmoralidad, la crudeza del drama o el encadenamiento de acciones excesivamente escabrosas que afectaba a la sensibilidad del público - a pesar de las supresiones de la traducción (Caldera, 2002: 245-253) -:

En cuanto al argumento, nos dispensaremos de referirle porque semejantes asuntos pierden infinito queriéndolos explicar; pierden lo único bueno que pueden tener y que la Lucrecia tiene, que es la manera de expresar ciertos afectos, el lenguaje de la pasión que brilla el grande ingenio del autor, y la delineación de algunos caracteres. De suerte que no viendo la representación, no oyendo el diálogo, de nuestra explicación descarnada ninguna otra cosa se inferiría que un tejido de acciones depravadas, disolución, adulterios, incestos, asesinatos, envenenamientos, parricidios... De todo esto hay en el drama; los vicios más hediondos, los crímenes más atroces representados ipuestos en toda su deformidad a la vista del público! (Correo de las Damas, 28-vII-I835: 220).

Del posicionamiento de Bretón con respecto a las escenificaciones de Víctor Hugo y de las variaciones de su criterio sobre la escuela romántica se ha ocupado Miret i Puig (2004: 139-152). Nos interesa ahora su apreciación de Concepción Rodríguez, que encarnó a la protagonista femenina, y a la que acompañaron Carlos Latorre y Julián Romea. Para Bretón:

No cabe mayor destreza que la manifestada por la dama en el arduo desempeño de su papel; sobre todo no se concibe que pueda representarse mejor que ella lo hace la escena en que habiendo empleado en vano mil arbitrios para desarmar la cólera de su marido contra Genaro, devora su inquietud, su rabia, su despecho, y se esfuerza a rendirle empleando las tretas de la más refinada coquetería; ni se imagina que a las maldiciones fulminadas sobre ella por el ídolo de su corazón, pueda una critatura humana responder con más afecto, con más dulzura: ¡bendito seas! (La Abeja, 2I-VII-I835: 2).

«La impura, la infernal Lucrecia» ofrecía un despliegue de lucimiento para la actriz, que debía resolver, de nuevo, un cierre en el que exhala sus últimas palabras - anagnórisis incluida en la que reconoce ser la madre de quien le está quitando la vida - (Cepeda [Gorostiza], I835: 80). El 23 de agosto interpretaba a Tisbe, una actriz-cortesana, criada en la mendicidad, en Ángelo, tirano de Padua, original también de Víctor Hugo. Su estreno en París, verificado el 28 de abril anterior, suscitó la curiosidad del público — se mantuvo con treinta y seis funciones hasta el 20 de junio (Miret i Puig, 2004: I4I)—, más interesado por el enfrentamiento entre las dos grandes actrices protagonistas, Marie Dorval y Mlle. Mars, que en el drama en sí. ${ }^{21}$ Esta última, consciente de la importancia de los

2I El enfrentamiento terminó en la parodia Cornaro, tyran pas doux (Martin-Fugier, 2008: 109). 
momentos efectistas, convenció al poeta para que modificara las últimas réplicas de Tisbe y conseguir, así, que el telón cayera, mientras expiraba, tras su breve : «Par moi, pour toi!» (Ambrière, 1992: 321-340; Hugo, I835: 105). En la edición impresa de la traducción española, que seguiría a la versión original de Víctor Hugo, se prolonga la agonía — con voz cada vez más apagada - de Tisbe (Parte II, III, 3):

Voy a morir. Tú pensarás algunas veces en mí, y dirás: «era una buena mujer la pobre Tisbe;» y yo me regocijaré, si puedo oírlo en el sepulcro. Adiós —Señora-, permitidme que le diga otra vez, iRodolfo mío!-Adiós, mi Rodolfo.-Partid al momento.-Me muero.—Vivid.-Yo te bendigo. Expira. (Hugo, I835: 106)

Las valoraciones de la interpretación de Mlle. Mars no fueron unánimes, pero algunas aplaudieron su conjunto y lo consideraron superior al de su rival: «Mlle. Mars courtisane, appelant à son aide toutes les ressources de son art, n'avait jamais été si fière, si dédaigneuse, si retranchée dans sa dignité ; elle réhabilitait véritablemente cette Tisbé, en lui prênant ses belles manières, cet admirable langage, cette noble démarche [...]» (cit. por Martin-Fugier, 2008: I08-I09). También la prensa española supo ver la superioridad de este personaje frente al de Catalina. Bretón, por ejemplo, dedicó una parte considerable de su análisis a los caracteres de Tisbe y Rodolfo. El crítico destacaba, con una retórica similar empleada en la apreciación a su homóloga francesa, cómo la primera dama había resuelto la actuación, sobre todo, de las últimas escenas:

Con admirable inteligencia, y aunque en todas sus escenas ha correspondido a la alta opinión que su gran talento artístico ha merecido, dudamos que haya actriz en el mundo capaz de serlo con expresión más veraz, más elocuente, más arrebatadora que la que ella ha desplegado en su escena del acto último en Rodolfo; y sobre todo cuando este, después de amenazarla con un puñal la dice que «nunca la habia amado» y ella exclama con toda el alma en los labios: jesa palabra es la que me mata, no tu puñal, desventurado! (La Abeja, 27-VIII-I835:3).

El desarrollo de la acción y el «derroche semiológico» (Miret i Puig, 2004: I4I) de la escenificación que el crítico detalla en su reseña, revela la energía que suponía para un actor, mínimamente comprometido, ejecutar con solvencia esta y otras piezas análogas. El estudio que, por ejemplo, Ribao (I999) realiza sobre los estrenos del canon romántico español, también contribuye a este acercamiento. No es extraño, pues, que en los certificados médicos que los actores presentan a la autoridad competente por la imposibilidad temporal de trabajar o bien que acompañan a sus solicitudes de jubilación se remita al cansancio físico, a determinados cuadros nerviosos o se diagnostiquen patologías relacionadas con una sobreexposición de lo físico o de la voz. La propia Matilde Díez, tan alabada por su voz, abandonará momentáneamente la escena en $185_{2}$ (AVM, Secretaría 4-16I-5) por esto último motivo. Los certificados de los médicos que presentó, por ejemplo, Antonio Guzmán para su jubilación en febrero de I837 describían los graves síntomas que padecía y que eran fruto de los «muchos desvelos, continuados trabajos y violentos esfuerzos a que se ha entregado durante los años que lleva de ejercicios de escena, y por las pasiones de ánimo deprimentes de que ha sido víctima» (AVM, Secretaría I-I86-45). ${ }^{22}$

$22 \mathrm{El}$ actor solicitaba la pensión de veintidós reales y medio, la de las primeras figuras, y no los dieciocho de su categoría. Concepción Rodríguez estaba en lo cierto cuando afirmaba que exigía prerrogativas que no le correspondían (AVM, Corregimiento I-I86-45). 
Con argumentos similares se presentaba la de Concepción Rodríguez, dirigida al Corregidor el 27 de febrero de 1836 (AVM, Secretaría 2-476-I). El propio Larra en la crítica a Teresa - traducción de Ventura de la Vega a partir de Alejandro Dumas, estrenada a principios del mismo mes- anotó como única apreciación de su trabajo que «salió como acostumbra del papel que le estaba cometido, si bien nos parece de algún tiempo a esta parte se descuida y debilita» (El Español, 5-II-I836: 4). La actriz exponía que el cansancio se había agravado con «la introducción del nuevo género dramático»; esto es, con el drama romántico, pues hace mención explícita a los dos textos de Víctor Hugo que acabamos de comentar: ${ }^{23}$

Da Concepción Rodríguez, primera actriz de los Teatros de esta Corte, a VE. con el debido respeto expone: que sus notorios esfuerzos en el desempeño de la trabajosa parte que le ha tocado en dichos teatros han alterado su salud al punto de obligarla por dos veces a suspender sus tareas, a saber en el año de I826 y en el de I832. No pidió sin embargo en aquellas ocasiones la jubilación que le correspondía, porque conservaba la esperanza de recobrar en breve fuerzas suficientes para restituirse a la escena. Pero la introducción de un nuevo género dramático infinitamente más cansado para los actores que el que le precedió, acabó con sus ya alteradas facultades físicas, y desde la Cuaresma pasada se hubiese retirado definitivamente del teatro a no haberla comprometido a seguir un año más las reiteradas insistencias de la Empresa.

Cara le ha costado esta condescendencia, porque la ejecución de dramas como Lucrecia Borgia, Ángelo y otros de igual naturaleza han agravado sus achaques hasta el extremo de hacer ya dudosa su cura y de poner en riesgo su existencia, como consta de las dos certificaciones adjuntas, dadas por los acreditados profesores D. Manuel de Codorniu y D. Gregorio Escalada.

E1 primero recomendaba abandonar la escena por estar «afectada de una neuralgia gastrocefalítica, cuyos paroxismos de carácter crónico, la han impedido muchos días el ejercicio de su clase; o la han obligado a trabajar con náuseas, vómitos y violentos dolores», mal agravado por su entrega en el último año. Por su parte, Gregorio Escalada, quien le había asistido con anterioridad por «una afección del aparato gástrico de carácter nervioso, que afectaba en ocasiones al órgano encefálico, o cerebral, originado indudablemente de los esfuerzos con que violentaba su físico en el desempeño de su arte», aconsejaba también la retirada. Así lo pedía la actriz, a la que:

Tales achaques, unidos al natural cansancio que deben haber producido en la exponente veinte y dos años de ímprobo y continuo trabajo, la reducen a la imprescindible necesidad de renunciar por un tiempo indefinido al ejercicio de su arte, si bien con harto sentimiento, y con no corto perjuicio de sus intereses; y solicitar la jubilación que le corresponde en razón de haber prestado en estos teatros catorce años de buenos, útiles y honrosos servicios.

La exposición, como era preceptivo, pasó a los apoderados de los actores para la jubilación, a la empresa y a la Comisión de Teatros del Ayuntamiento (Carrière, I980: 229-24I).

23 La actriz interpretó estas dos piezas embarazada. Su tercera hija, Leopoldina, nació a finales de I835 (Gies, I988: I23). 
Se encargó informe a otros dos facultativos desginados por esta última, Pedro Suárez y Pedro Videl, quienes evacuaron, el 24 de abril, el siguiente:

hallamos que sus padeceres físicos son proporcionados a los notorios, excesivos y bien estudiados esfuerzos morales, por los que ha logrado siempre conmover y agradar las pasiones del ilustrado público de esta Corte; con cuyo motivo, resentido su sistema nervioso cerebral, ha padecido por repetidas ocasiones Neuralgia de diverso carácter, según consta por las certificaciones de los facultativos que en distintas épocas la han asistido, según también uno de los que firmamos la ha observado en alguna ocasión, por lo que somos de opinión que esta actriz en la actualidad se halla en un estado de tal susceptibilidad nerviosa, que la menor causa excitante sería suficiente para que agravándose quedase absolutamente imposibilitada para siempre del uso de su profesión, y por lo tanto la juzgamos Inútil en la ocasión presente y hasta que se reforme de su alterada salud, para poder dedicarse al ejercicio activo de su facultad.

El 29 de abril se aprobó oficialmente su jubilación con una pensión de veintidós reales y medio. Mientras se resolvía el expediente y concluía la temporada teatral, estrenó un nuevo drama romántico, El trovador, de Antonio García Gutiérrez. Larra lo analizó con profusión. Con respecto a los personajes principales, consideraba que el más interesante era el de la gitana, que encarnó Bárbara Lamadrid y que hubiera debido desempeñar Concepción Rodríguez:

Esta es la creación más original, más nueva del drama, el carácter más difícil también, y, por consiguiente, el de mayor lucimiento: si la señora Rodríguez es la primera actriz de estos teatros, ella debiera haberlo hecho, y aunque hubiese estado fea y hubiese parecido vieja, si es que la señora Rodríguez puede parecer nunca fea ni vieja. El carácter de Leonor es de aquellos cuyo éxito está en el papel mismo; no hay más que decirlo. Una actriz como la señora Rodríguez debiera despreciar triunfos tan fáciles (Larra, 2010: 236 ). ${ }^{24}$

No obstante este aviso, el crítico señala el momento más significativo de su actuación, que «nos recordó sus mejores tiempos, y dijo con una expresión muy feliz casi todos sus diálogos» (Larra, 20ıo: 236), el final de la primera parte del acto v — v, 7 (García Gutiérrez, I892: 66); Larra confunde la referencia pues da v, 5-:

Enamorada del trovador y con un veneno en el cuerpo, debía aparentar sucumbir con cierta indiferencia a los deseos de don Nuño; cuando dice don Nuño, hablando del trovador:

Un hombre oscuro,

y ella responde: sí, sí...Nunca mereció mi amor,

Lo dijo con tal verdad, que un murmullo atronador se hizo sentir, de aquellos que revelan espontáneamente en los espectadores una profunda simpatía con el actor: de aquellos que quieren decir que este acaba de herir la cuerda sensible. Tenemos tanto más placer en hacer esta justicia a la señora Rodríguez, cuanto que 
hace algún tiempo había merecido de nuestra imparcialidad alguna reconvención (Larra, 2010: 237).

La reseña suena a despedida, que aprovecha, en fin, para reconocer los justos méritos de toda una trayectoria. Tuvo oportunidad de hacerlo una vez más. La actriz abandonaba la escena encarnando a la protagonista Catalina Howard, del drama homónimo de Alejandro Dumas, en traducción de Narciso de la Escosura. El estreno se verificó el r6 de marzo. Para Larra, su actuación: «nos ha convencido de que nadie puede reemplazarla en su buena dicción y en la verdad sorprendente con que ha hecho varias escenas; su resurrección sobre todo nos ha parecido excelente, y el sueño delante del rey» (ElEspañol, 23-III-I836: 4). Más profusa fue la despedida de Bretón de los Herreros, consciente de que le debía gran parte de su éxito como dramaturgo y traductor:

¿Dónde hubiera hallado más digno intérprete que en ella ese arduo carácter de Catalina Howard, confuso caos de tiernos afectos, de mujeriles ardides, de encontradas vehementes pasiones, alumbrado con siniestra y fúnebre luz por el astro fatídico de una insensata ambición? Yo que en parte soy deudor al raro talento de esta grande actriz de algunas flores que la bondad del público madrileño se ha dignado de esparcir por entre las espinas de la carrera dramática que sigo con invencible pasión, ¿cómo podré dejar de interesarme en este nuevo triunfo de la inimitable Concha? ¡Plugiera a Dios que no fuese el postrero como nos lo han anunciado! ¿Y será posible que ese luminar de la escena española se oculte voluntariamente cuando más radiante y vigoroso puede y debiera brillar? ¿Y quién la reemplaza ahora? Podrá haber quien la supla hasta cierto punto en pocos papeles; ¿mas dónde hallar una actriz tan inteligente, tan sensible, tan infatigable, tan universal? ¡Pérdida es irreparable para el público, para los empresarios y para los poetas! (La Abeja, 2O-III-I836: 2).

El día anterior a esta crítica, el mismo diario insertó «Un sueño. La actriz», poema en reconocimiento a toda su trayectoria. La composición, en la que está presente Isidoro Máiquez y los grandes poetas dramáticos, recorre los personajes encarnados por Concepción Rodríguez: Dido, Gabriela de Vergy, Catalina Howard, y también los textos de Víctor Hugo: «La escena española perdió su ornamento; / los vates tu ausencia maldicen tal vez; / y sorda a cien ruegos dejaste la escena, /que tantos aplausos valiérate y prez. / En esa que miras, tristísima tumba, / un genio descansa de nombre inmortal... / Intérprete augusta de Tisbe y Lucrecia, / la máscara deja y con ella el puñal». Los apóstrofes finales volvían a preguntarse por la posible heredera: «¿Do la elegida está que te sucede / Concha, la sola actriz de España entera? / La corona y la máscara ligera, / ¿quién? ¿quién, después de ti tomarlas pueda?» (La Abeja, I9-III-I836: 4 ). ${ }^{25}$

La respuesta estaría en la joven primera dama Matilde Díez, quien había desempeñado esa temporada parte de los primeros papeles, en especial, sobre el escenario del Teatro de la Cruz. Interpretó, son solo unos ejemplos, Incertidumbre y amor, de Eugenio de Ochoa — La Revista Española alaba su trabajo, pero solicita el pase al Teatro del Príncipe, pues

${ }_{25}$ El ejemplar consultado que se custodia en la BNE está mal cortado de manera que se pierden las últimas líneas de los versos y la posible firma del autor — no sabemos si Bretón- En cualquier caso, la composición se introducía así: «Retirándose definitivamente de la escena la Sra. Concepción Rodríguez, hemos creído oportuno insertar la siguiente composición escrita en su elogio. El mérito de aquella actriz es universalmente conocido: creemos por lo tanto que nuestros lectores verán con gusto los acentos que ha arrancado a la lira de uno de sus muchísimos apasionados». 
lo considera mejor equipado, y un repertorio más ambicioso (3-VI-I835: 386-387)—; La novicia o La victima del claustro, traducción de Carnerero (Revista Española. Mensajero de las Cortes,3-VII-I835: 405); ¿̇Se sabe quién gobierna?, traducción de Bretón, y El pan, pan y el vino, vino (Revista Española. Mensajero de las Cortes, 5-X-1835: 269-270); El ambicioso o La dimisión de un ministro, comedia en cinco actos traducida por Ventura de la Vega -José de Espronceda la reseña con admiración en El Artista (t. I, I835: 204)—; Ricardo Darlington y El Duque de Braganza, ambas en traducción de Covert-Spring, pseudónimo de Josep Andreu Fontcuberta (Saura Sánchez, 2003: 579-590 y 2006: 205-2II), del que estrenará otros trabajos en Barcelona. De sus cualidades es buena muestra su actuación en $\mathrm{La}$ gata mujer, programada el 24 de julio en el Príncipe junto con El marido de todas, La corrección singular y un baile final. El reseñista de la Revista Española. Mensajero de las Cortes consideraba un tanto indigno que una primera dama tuviera que remedar a un felino, si bien lo que interesa son los recursos de la actriz para resolver el papel encomendado:

La señora Matilde Díez, eterna protectora y salvaguardia de autores y traductores, fue quien más contribuyó, no solo a que se sostuviera, sino a que, al caer el telón se oyeran aplausos que hicieron callar los silbidos y chicheos de algunos descontentadizos. No se puede dar más naturalidad y gracia que la de esta joven actriz en el desempeño de su difícil papel. Aquel gatesco refunfuño que da al asomarse por primera vez al espejo, aquel pasarse las manos por la cara a la manera gatuna, aquel suelto jugar con los ovillos, en fin, aquellos desagradables gestos a que la obligaba su ridículo papel, nos daban lástima y grima, y nos llenaban al mismo tiempo de contento (26-VII-I835: 590).

En diciembre de 1835 , Carlos Rebollo traslada a la Reina gobernadora su voluntad de rescindir la contrata, apremiado por las deudas ocasionadas, entre otras, por la epidemia de cólera y la coyuntura bélica. En abril de 1836 se rescinde y se firma la nueva, por la que los actores Carlos Latorre, José García Luna y Antonio de Guzmán asumen la empresa. Matilde Díez termina contratándose en Barcelona - al parecer por desacuerdos con sus compañeros, pues estaba previsto que formara parte de ella- (Ballesteros Dorado, 20I2, II: 199-203 y 299-306; AVM, Secretaría 2-480-53). Bretón de los Herreros reseñó su función de despedida, programada el 24 de marzo en el Teatro del Príncipe. Anotó que debería haber escogido un repertorio más ajustado a sus capacidades. Del espectáculo, compuesto, como indicamos al inicio del artículo, por Querio ser cómico, Clotilde y No más muchachos, parecía ajustarse, por su naturaleza cómica, a la primera pieza. El de Clotilde: «aunque lo ejecuta con inteligencia y con la expresiva sensibilidad que es una de las dotes que más la recomiendan, requiere otra figura más a propósito para representar la mímica de las grandes pasiones, y acaso exige también más práctica del género a que dicho papel pertenece». El poeta se hacía eco, no obstante, del calor con el que el público se despidió de ella: «Nosotros que siempre nos hemos complacido en reconocer y aplaudir el de esta interesante actriz, la felicitamos cordialmente por tan satisfactoria despedida, y envidiamos al teatro de Barcelona la dicha de poseer en la temporada próxima a una de las joyas más preciosas de la escena española» (La Abeja, 26-III-I836: I).

En Barcelona tendría oportunidad de seguir los consejos del crítico, pues aprovechó para consolidar y ampliar su repertorio. El 29 de marzo, el Diario de Barcelona publicó la lista de actores de las compañías española y de ópera que trabajarían en el Teatro de la Santa Creu (Sansano, 2021: 325-332) durante la nueva temporada que se extendería desde el 3 de abril de ese año hasta el 7 de febrero del siguiente. Ese año se incorporaron dos nuevos puestos destinados a la parte artística: un poeta dramático y el pintor y director 
de maquinarias; que desempeñarían Covert-Spring y Buenaventura Planell (Fàbregas, I975: 88-92; Sala Valldaura, 2000: I75). El autor de la compañía española era Luis María Calderón y el director de escena y primer galán: Joaquín Alcázar a quien supliría, como sobresaliente, Antonio Valero. Matilde Díez figura como la única primera dama. Juana Galán se contrata como sobresaliente y María Cañete, dama joven, también tendría que suplirla en caso necesario (Diario de Barcelona, 29-III-I836: 715-716). En julio se sumó, por unos meses, Julián Romea. ${ }^{26}$ Matilde Díez se presentó el sábado 23 de abril con El colegio de Tonnington, que El Vapor reseñó tres días más tarde. La crítica insiste en la expectación de la llegada de la actriz que justifica la alta concurrencia. Se recrea en el momento exacto en que aparece por primera vez:

Levántase el telón, y un profundo silencio era ya un tributo pagado al alto concepto que la joven actriz ha sabido adquirir en la capital de la Monarquía entre los literatos más adelantados de nuestra época. Un solo murmullo se oía de cuando en cuando y era el eco mil veces repetido de estas frases: «ंCuándo sale?» — «Es aquesta?»- Los que tenían conocimiento del drama deseaban que el primer acto pasase como un relámpago a sus ojos.

Por fin, sale la interesante joven, tanto tiempo deseada, y, lo diremos otra vez, al verla tan niña, muchos de los espectadores iban ya a creer exageradas las noticias recibidas. La linda Educanda, en el segundo acto, nos hizo ver a una niña inocente, producto de la falsa educación que se las da en casi todos los colegios europeos, y mucho más en la época del drama; porque Matilde tiene el talento, nunca bien ponderado, de no salir jamás del papel que representa, aunque sepa que una ligera exageración va a ser pagada con usura. Ya en este acto, se admiró su naturalidad, su voz, — ¿quién resiste a la voz de Matilde? — Su voz se halló, cual es, dulce, armoniosa, de aquellas que llegan al corazón más sensible; pero en el tercer acto, ¡oh! entonces el hombre más apático, el ser más frío, tuvo que pagar tributo a la verdad. ¿Puede haber nada más natural, ni más deliciosamente expresado, que el encogimiento que produce en Elena la sorpresa de Tom Love, y el precipitado tartamudear con que, echándose en el sillón, responde a las primeras palabras de su amante? ¿Y la inmovilidad con que escucha su declaración? ¿Y aquella sublime transición de la natural timidez, que infunde en una niña los primeros juramentos de un amante, a una instintiva y súbita alegría? (El Vapor, 26-IV-1836: 4).

El entusiasta reseñista concluía con un contundente: «todos dirán muy pronto, con un amigo nuestro, que la naturaleza formara a Matilde para la escena, del mismo modo que a Napoléon para la guerra», y firmaba con la sigla X. Detrás se ocultaba el poeta dramático de la compañía, alguna de cuyas traducciones ya había estrenado en Madrid y que volverá a interpretar en esta temporada: Ricardo Darlington, El Duque de Braganza, a las que sumarán Chitón y Napoleón lo manda. Fontcuberta le dedicará elogiosas críticas según avanza la temporada. ${ }^{27}$ Reseña otros títulos, como El trovador, que presenta en mayo, donde relaciona su interpretación con la de su predecesora Concepción Rodríguez:

26 El matrimonio de Julián Romea y Matilde Díez se celebró en Barcelona por poderes el 28 de octubre de 1836. Se ratificó en la Parroquia de San Sebastián de Madrid el I4 de febrero de i837. A los pocos años se separaron pero continuaron trabajando juntos en distintas temporadas escénicas (Soria Tomás, 2010: I64-165).

27 No exentas de polémica que suscitaron varias réplicas y contrarréplicas con El Guardia Nacional. Por cuestiones de espacio no puedo detenerme ahora en ello. Pretendo tratar de esta cuestión en futuros trabajos. Para un primer acercamiento a su trayectoria escénica ver Menarini (2002: 163-I77). 
El papel de Leonor ha sido el segundo y más completo triunfo de Matilde en nuestro teatro. Aquellos que suspendían su juicio, por no confesar que arrastraban la pesada cadena de una preocupación ridícula, se han declarado convertidos. [ं] Quién es capaz de dudar ya, que Matilde, en este momento, es la $\mathrm{I}^{\mathrm{a}}$ actriz de la península?

La Sra. Díez no reproduce las maneras de Da Concepción Rodríguez ni sigue su filosófica escuela. Matilde no imita ni copia; la sublime expresión de su mímica la encuentra en su corazión, porque la naturaleza la formó para el teatro. Con esta declaración, que nos arrancan la imparcialidad y la justicia, pretendemos rectificar un error, que ninguno de los escritores modernos que más conocen a Matilde, pueden dejar sin respuesta. Y no se crea por esto que tratemos de disminuir en lo más mínimo el sobresaliente mérito de la Sra. Rodríguez, a quien pagamos más de una vez nuestro tributo en los periódicos de la corte, y cuya pérdida para el teatro, sentimos infinito; pero hay pocos puntos de comparación entre ambas actrices y no sabemos cómo pudiera sostenerse lo contrario (El Vapor, 24-V-1836: 4).

Manuel González dedicó un poema a esta interpretación de Matilde Díez en las páginas de El propagador de la libertad (t. III, I838: I3-I6), publicación en torno al romanticismo liberal que encabezaba Fontcuberta y en la que este vuelve a editar parte de las críticas de El Vapor (Bacardit y Gibert, 2003: 26-27, 34-37, 78-82). La actriz se incorporó, además, como miembro residente a la Sociedad Filodramática que se acababa de instituir por mediación del traductor (El propagador de la libertad, t. III, I838: 223; Fàbregas, I975: 279). Concluida la temporada, regresa como primera dama al Teatro de la Cruz (MNT, 3452; Eco del Comercio 27-III-I837: 8). Se presentó con Clotilde el 4 de abril. La prensa reseñó la buena acogida del público (El liberal, 5-IV-I837: 3) y la actuación se celebró con una oda insertada en El porvenir (27-V-I837: I-2).

Por su parte, Concepción Rodríguez se reunía en I837 — seguramente tras tener a su hija Cecilia - con Juan de Grimaldi en Francia (Gies, I988: I24 y 230). El director había abandonado Madrid precipitadamente en agosto del año anterior, después del Motín de la Granja, temeroso de las represalias que sus escritos en favor de los moderados pudieran ocasionarle. David T. Gies se ha ocupado de sus relaciones influyentes, su labor como Cónsul de España en París y los distintos negocios que emprendió (I988: I35-I8I). Concepción Rodríguez otorgó, en años posteriores, poderes para cobrar la pensión de jubilación de los teatros de Madrid: en I837, a favor de su padre Bruno Rodríguez; en I840, a favor de su esposo - para administrar todos sus bienes-; en I844, al del actor Carlos Latorre; en I849, a Marcos Barón (AHPM, T. 25563, f. I9; T. 25565, ff. 89-9o; T. 25567, f. 34bis; T. 32013, pp. 32-33). Desde junio de I844 la prensa tanto nacional como francesa recogía el viaje de Matilde Díez a París (Revue de Paris, mai-août 1844: 313; Revue des deux mondes, t. III, I844: IoI; Revista de Teatros, 26-VI-I844: 2; El Espectador, 28-VI-I844: 4; El Heraldo, II-VIII-I844; El Laberinto, I6-VIII-I844: 280). Alguna cabecera aventuraba un encuentro entre maestra y discípula:

La célebre actriz española Doña Matilde Díez ha pasado a París durante el verano. Interesante debe ser el resultado de su viaje, si bien poca envidia podrán causarle los triunfos que adquieren las célebres actrices francesas. No dejará de visitar en aquella capital a su antigua compañera y maestra la memorable Doña Concepción Rodríguez, cuyo prematuro retiro ha privado a la escena española de una de sus más apreciables notabilidades (Revista balear, I4-VII-I844: 3). 
Según distintas necrológicas, Concepción Rodríguez falleció el 27 de diciembre de 1857 (El Museo Universal, 30-XII-I857: 2I2; La España, 3I-XII-I857: 3; La Esperanza, 2-II858: 4). Matilde Díez prosiguó su carrera como primera dama hasta I878 (MNT, 3452; AVM, Secretaría 6-354-58). En ella confluyen los distintos elementos de profesionalidad artística y de reconocimiento social que la identifican como una de las grandes actrices del xix. Por Real orden de 20 septiembre de $185 \mathrm{I}$ se le nombró primera actriz del Real Teatro de Palacio, para el que interpretó varias funciones durante el corto tiempo en que estuvo abierto (AGP, Personal, C ${ }^{a}$ I6852, expt. 27; Subirá, I950). En I852 solicitó licencia para realizar una gira por Cuba y México, que verificó entre I853 y I858 (AVM, Secretaría 4-I04-23; 4-I6I-5) y de la que dio, en parte, testimonio la biografía La perla del teatro español, publicada en México (I855). Fue la primera mujer nombrada catedrática de Declamación en la Escuela Nacional de Música, labor que desempeñó entre 1874 y enero de I883, cuando falleció (AGA, 31/14750; ARCSMM, Exptes. Personal. Matilde Díez; Soria Tomás, 2015: 49-66 y 2020b: 369-400). Su sepelio, como el de otras grandes actrices, supuso un suceso memorable, señal de reconocimiento y popularidad (El Liberal, I8-II883: 2; La Ilustración Española y Americana, 22-I-I883: 52). A ella contribuyó, además, la multiplicación de su imagen y la de los miembros de su familia en forma de retratos - los de Esquivel son un buen ejemplo- de litografías, fotografías o comerciales, que prolongaron su recuerdo en el tiempo (Gracia Beneyto, 1997: 4II-478; Simón Palmer, 2002: I7-I8; Gómez Todó, 20I4: 45-98).

\section{Conclusiones}

En las páginas anteriores hemos documentado la biografía artística de Concepción Rodríguez, gran dama de la escena española en las primeras décadas del xix, y su relevo por Matilde Díez. El estudio de una selección de su repertorio más significativo y su recepción crítica muestra la estrecha relación entre poeta e intérprete. La retórica que las crónicas emplean para analizar sus trabajos remiten a conceptos que pueden resultar problemáticos, por su propia historicidad, tales como naturalidad o verdad. En cualquier caso, las apreciaciones se detienen en cualidades vocales, sensibilidad y capacidad expresiva para interpretar y trasladar al espectador las distintas emociones. Con frecuencia, las críticas analizan con detalle determinada acción de las intérpretes que convierten en modélicas para futuros actores. Es el caso de Dido y su trasvase a la tratadística escénica. No son comentarios que se limitan a insistir en el patrón femenino moralmente aceptado, aunque parte del católogo de personajes que encarnaban estuviera destinado a consolidarlo. Las apreciaciones que contienen estas reseñas responden, en ocasiones, a lugares comunes y son similares a las que recibieron las actrices francesas coetáneas, con quienes, de otro lado, se las compara.

La maestría en la escena une tanto a Concepción Rodríguez como a Matilde Díez con el primer centro de formación reglada para artistas escénicos: La Escuela de Declamación Española. La primera como Maestra honoraria a la que se le reconoce su larga trayectoria. La segunda, como primera catedrática en ejercicio. Esta vinculación contribuyó a la rehabilitación social de la profesión, una de las características de la cultura de la sociedad burguesa. El tratamiento de Doña funciona como síntoma de esta aceptación. Su imagen pública se multiplica a la vez que la privada no siempre sigue los cánones sociales moralmente aceptados.

Los documentos que sustentan nuestra investigación contribuyen a conocer la dinámica de trabajo al que se sujetaba una primera actriz así como las consecuencias físicas que esta acarreaba. A su vez, es buena muestra de la aceptación y reconocimiento que 
público, crítica y apasionados les brindaban, como testimonian las composiciones poéticas que hemos presentado. Por último, la horquilla temporal del estudio, centrado en la década de los 30 del xix, propicia un acercamiento a la cartelera teatral del periodo - muy rica por la variedad de géneros, el desarrollo del drama romántico y la adaptación de las modas literarias extranjeras- desde el punto de vista de la práctica escénica.

\section{BiBLIOGRAFÍA ${ }^{28}$}

A. [Grimaldi, Juan de] (1835), «Biografía. Doña Concepción Rodríguez», El Artista, xviI, t. II, pp. 193-196.

Aguilar Piñal, Francisco (ig68), Cartelera prerromántica sevillana. años I80o-I836, Madrid, CSIC. Álvarez Barrientos, Joaquín (2019), El actor borbónico (I700-I83I), Madrid, ADE.

— (I988), «El actor español en el siglo xviII: formación, consideración social y profesionalidad», Revista de Literatura, $\mathrm{n}^{\circ}$ Ioo, pp. 445-466.

Ambrière, Francis (1992), Mademoiselle Mars et Marie Dorval au théâtre et dans la vie, París, Seuil. Anderson, Bonnie S. y Zinsser, Judith P. (1992), Historia de las mujeres: una historia propia, vol. 2, Barcelona, Crítica.

Andioc, René (1982), «Sobre el estreno del Don Álvaro», en José Amor y Vázquez y A. David Kossoff (eds.), Homenaje a Juan López-Morillas: de Cadalso a Aleixandre, estudios sobre la literatura e historia intelectual españolas, Madrid, Castalia, pp. 63-86.

Bacardit, Ramon y Gibert, Miquel M. (2003), El debat teatral a Catalunya. Antologia de textos de teoria i crítica dramàtiques, Barcelona, Institut del Teatre.

Balmaseda, Joaquina García (188I), «La actriz española», en Faustina Sáez de Melgar (ed.), Las mujeres españolas, americanas y lusitanas pintadas por sí mismas, Barcelona, Juan Pons, pp. 63-77.

Ballesteros Dorado, Ana Isabel (2012), Manuel Bretón de los Herreros: más de cien estrenos en Madrid (I82I-I840), 2 vols., Logroño, Instituto de Estudios Riojanos.

— y CRUZ, José (20I5), «Segunda etapa: I833-I868», en Fernando Doménech y Eduardo Pérez-Rasilla (coords.), Historia y antología de la crítica teatral española (1763-1936), Madrid, INAEM, pp. I6I-180.

Barba DÁvalos, Marina (20I4), «La figura de la canta-actriz en el drama romántico español durante la Regencia de María Cristina de Borbón», Quadrivium, no ${ }^{5}$. En línea.

Bastús y Carrera, Vicente Joaquín (2008), Tratado de Declamación o Arte Dramático, Eduardo Pérez-Rasilla y Guadalupe Soria Tomás (eds.), Madrid, Fundamentos.

- (1865), Curso de Declamación o Arte Dramático aprobado por SM para la enseñanza del Real Conservatorio de Música y Declamación de Madrid, Barcelona, Imp. y librería de Salvador Manero.

Bautista Alonso, Juan (1834), Poesias, Madrid, Imp. de Don Tomás Jordán.

Blasco, Eusebio (1888), Malas costumbres. Apuntes de mi tiempo, Madrid, Oficinas de la Ilustración Española y Americana.

Bretón de los Herreros, Manuel (1965), Obra dispersa. I. El Correo Literario Mercantil, Juan María Díez Taboada y Juan Manuel Rozas (eds.), Logroño, Instituto de Estudios Riojanos.

- (1831), Poesias, Madrid, Imp. de D. Pedro Ximénez de Haro.

_ (1827), Dido, tragedia en 5 actos traducida del francés, Madrid, Imp. de Don Miguel de Burgos.

28 No se incluyen las fuentes archivísticas y hemerográficas específicas, que pueden localizarse a lo largo del artículo. 
Caldera, Ermanno (2005), «La liberalización "teatral” de la mujer en las primeras piezas románticas», en Luis Díaz Laños et al. (eds.), Lectora, heroina, autora. La mujer en la literatura española del siglo XIX, Barcelona, Universitat de Barcelona, pp. 57-63. En línea.

- (2002), «La Lucrecia Borgia que se estrenó en el Teatro del Príncipe», en Francisco Lafarga, Concepción Palacios y Alfonso Saura (eds.), Neoclásicos y románticos ante la traducción, Murcia, Universidad de Murcia, pp. 245-253.

- (200I), El teatro español en la época romántica, Madrid, Castalia.

CARrière, Ma Thérèse (I980), «Acerca de las pensiones de actores en la Cruz y el Príncipe a mediados del siglo XIX», en Homenaje a Jean-Louis Flecniakoska, I, Montpellier, Université Paul Valéry, pp. II9-I4I.

Cartelera teatral Madrileña I: años 1830-I839 (196I), Madrid, CSIC.

Catalán, Ma Soledad (2002), «Los actores en la vida teatral madrileña entre 1828 y i836. (Sus litigios con los empresarios y su formación)», Crítica Hispánica, xxIV, nº I-2, pp. III-I3o.

Cepeda, Ángel [Gorost iza y Cepeda, Pedro Ángel de] (I835), Lucrecia Borgia, Madrid, Repullés.

Coca Ramírez, Fátima (2000), «La influencia de la “comedia sentimental” en la poética del "drama histórico" y de la "tragedia neoclásica” a principios del siglos XIx en España», Cuadernos de Ilustración y Romanticismo, no 8, pp. II5-I30. En línea.

Cotarelo y Mori, Emilio (2009), Isidoro Máiquez y el teatro de su tiempo, ed. Joaquín Álvarez Barrientos, Madrid, ADE.

- (1904), Bibliografía de las controversias sobre la licitud del teatro en España, Madrid, Establecimiento Tipográfico de la Revista de Archivos, Bibliotecas y Museos.

Chancerel, René (I930), L'évolution du statut des comédiens, París, Les presses modernes.

Dengler, Roberto (I99I), «Alcance de las traducciones de obras francesas en los repertorios teatrales madrileños entre I830 y I850", en Roberto Dengler (coord.), Estudios humanísticos en homenaje a Luis Cortés Vázquez, Salamanca, Universidad de Salamanca, pp. I6I-I69.

Doménech, Fernando (2003), Leandro Fernández de Moratín, Madrid, Síntesis.

Duffey, Frank M. (1942), «Juan de Grimaldi and the Madrid Stage (1823-1837), Hispanic Review, $\mathrm{X}, \mathrm{n}^{\mathrm{O}} \mathrm{I}, \mathrm{pp} \cdot \mathrm{I} 47^{-156}$

Duvignaud, Jean (I966), El actor. Bosquejo de una sociología del comediante, Madrid, Taurus.

Enciso Cast rillón, Félix (I815), El joven de sesenta años, Madrid, Francisco Martínez Dávila.

EscoвAr, José (1976), «Un episodio biográfico de Larra, crítico teatral en la temporada de I834», Nueva Revista de Filología Española, xxv, pp. 45-72.

Esteve, Josep-Joaquim (2008), La música al Teatre de Palma (I800-I8I7). L'efecte de la reforma ilustrada, Palma, Edicions Documenta Balear.

FÀbregas, Xavier (1975), Les formes de diversió en la societat catalana romàntica, Barcelona, Curial.

Fernández Cabezón, Rosalía (2013), «Crisis teatral en Madrid durante el Trienio Liberal», Revista de Literatura, t. LXXV, $\mathrm{n}^{\circ}$ I49, pp. I05-I20. En línea.

Freire, Ana María (2009), El teatro español entre la Ilustración y el Romanticismo. Madrid durante la Guerra de la Independencia, Madrid, Iberoamericana-Vervuert.

García Garrosa, María Jesús (I990), La retórica de las lágrimas. La comedia sentimental española (I75 $\left.{ }^{-I 802}\right)$, Valladolid, Universidad de Valladolid.

García Gutiérrez, Antonio (I892), El trovador, ed. Adolf Kresser, Leipzig, Rengersche Buchandlung.

Garcías Estelrich, Domingo (2005), Historia del teatro en Mallorca. Del Barroco al Romanticismo (I60o-I834), Palma, Lleonard Muntaner.

Gies, David T. (2009), «Genderama: Performing Womanhood in Nineteenth-Century Spanish Theatre», Hispanic Research Journal, 10, $\mathrm{n}^{\circ}$ 2, pp. 108-г21.

- (2005), «Romanticismo e histeria en España», Anales de Literatura Española, no I8, pp. 215-225. En línea. 
- (2002), «Otra vez Grimaldi: Bouilly, Ducange y “La huérfana de Bruselas” (I825)», en Francisco Lafarga, Concepción Palacios y Alfonso Saura (eds.), Neoclásicos y románticos ante la traducción, Murcia, Universidad de Murcia, pp. 309-318.

- (I996), El teatro en la España del siglo XIX, Cambridge, Cambridge University Press.

- (I988), Theatre and Politics in Nineteenth-Century Spain. Juan de Grimaldi as impresario and government agent, Cambridge, Cambridge University Press.

— (1985), «Larra, Grimaldi and the Actors of Madrid», en W. Douglas Barnette y LindaJean Barnette (coords.), Studies in Eighteenth Century Spanish Literature and Romanticism in Honor of John Clarkson Dowling, Newark, Juan de la Cuesta, pp. II3-I22.

Gómez Todó, Sandra (20I4), De cómicas a damas de la escena: representaciones de la actriz en España (I770-1870). TFM. Institut Universitari de Cultura / Universitat Pompeu Fabra. En línea.

Gracia Beneyto, Carmen (i997), «La iconografía del actor como documento», en Evangelina Rodríguez Cuadros (coord.), Del oficio al mito: el actor en sus documentos, 2 vol., Valencia, Universitat de València, pp. 4II-478.

Hugo, Víctor (1835), Ángelo, tirano de Padua, Madrid, Imprenta de Repullés.

La perla del teatro español. Biografía de la actriz Matilde Diez (1855), México, Imp. de F. Escalante y Comp.

LAfarga, Francisco (1983), Las traducciones españolas del teatro francés (I70o-1835). I. Bibliografía de impresos, Barcelona, Universitat de Barcelona.

Lamarca, Luis (I84I), Apuntes sobre el arte de representar, Valencia, Imp. de López y Cía.

Larra, Mariano José de (20Io), La crítica teatral completa de Mariano José de Larra, ed. Rafael Fuentes Mollá, Madrid, Fundamentos.

Larraz, Emmanuel (I980), «Le statut des comédiens dans la société espagnole du début du $\mathrm{XIX}^{\text {ème }}$ ", en Claude Dumas (ed.), Culture et Société en Espagne et en Amérique latine au XIX siècle, Lille, Université de Lille III, pp. 27-40.

Latorre, Carlos (I839), Noticias sobre el arte de la declamación, que pueden ser de una grande utilidad a los alumnos del Real Conservatorio, Madrid, Imprenta de Yenes.

Leslie, John Kenneth (1940), Ventura de la Vega and the Spanish Theatre (1820-I865), Princeton.

Martín, Gregorio C. (I988), «Los teatros madrileños bajo Grimaldi y Gaviria», Boletín de la Biblioteca Menéndez Pelayo, no LXIv, pp. 209-222.

- (I985), «Querer y no poder, o el teatro español de I825 a I836», en W. Douglas Barnette y Linda-Jean Barnette (coords.), Studies in Eighteenth Century Spanish Literature and Romanticism in Honor of John Clarkson Dowling, Newark, Juan de la Cuesta, pp. I23-132.

Martin-Fugier, Anne (2008), Comédiennes, Les actrices en France au XIXe siècle, París, Complexe.

Mas i Vives, Joan (2006), Diccionari del Teatre a les Illes Balears, vol. 2, Palma / Barcelona, Lleonard Muntaner / Publicacions de l'Abadia de Montserrat.

Melendres, Jaume (2000), La Dirección de los actores. Diccionario minimo, Madrid, ADE.

Menarini, Piero (2002), «El teatro como espacio para el debate: El caso de J. A. de CovertSpring», en Los Románticos teorizan sobre si mismos, Bolonia, Il Capitello del Sole, pp. I63-I77.

et al. (I982), El teatro romántico español (I830-1850). Autores, obras, bibliografía, Bolonia, Atesa.

Miret i Puig, Pau (2005), «La actriz como personaje en el teatro de Bretón de los Herreros» en Luis Díaz Laños et al. (eds.), Lectora, heroina, autora. La mujer en la literatura española del siglo XIX, Barcelona, Universitat de Barcelona, pp. 253-26o. En línea.

- (2004), «Bretón de los Herreros, crítico teatral ante el drama romántico francés», Salina, $\mathrm{n}^{\mathrm{O}} \mathrm{1} 8$, pp. I39-152. 
Mornat, Isabelle (2008), «Aceptación y mercantilismo literario: las actrices», en Pura Fernández y Marie Linda Ortega (eds.), La mujer de letras o la letraherida: discurso y representación sobre la mujer escritora en el siglo XIX, Madrid, CSIC, pp. 447-458.

Palacios, Emilio y Romero Ferrer, Alberto (2004), «Teatro y política (I789-1833): entre la Revolución Francesa y el silencio», en Joaquín Álvarez Barrientos (ed.), Se hicieron literatos para ser políticos. Cultura y politica en la España de Carlos IV y Fernando VII, Cádiz / Madrid, Universidad de Cádiz / Biblioteca Nueva, pp. 185-242.

Pascual, Eusebio (I883), «Un tesoro olvidado. Apuntes para una biografía», Almanaque balear para el año I884, Palma de Mallorca, Tipografía de Pedro José Gelabert, pp. I37-I46.

Pataky Kosove, Joan Lynne (1978), The comedia lacrimosa and Spanish Romantic Drama (1773-1865), Londres, Tamesis.

Peláez, Andrés (2000), «María Ladvenant y Quirante: primera dama de los teatros de España», en Luciano García Lorenzo (ed.), Autoras y Actrices en la historia del teatro español, Murcia, Universidad de Murcia, pp. 133-I53.

Rabaté, Colette (2007), ¿̇«Eva o María»? Ser mujer en la época isabelina (I833-I868), Salamanca, Universidad de Salamanca.

Reyes, Antonio de los (1977), Juliá Romea. El actor y su entorno, Murcia, Academia Alfonso X El Sabio.

Ribao, Montserrat (1999-2000), «La locura femenina como resorte espectacular. Obnubilación, delirio y demencia en el drama romántico», Letras Peninsulares, I2, no 2-3, pp. 185-200.

(I999), Textos y representación del drama histórico en el romanticismo español, Pamplona, EUNSA.

Roca de Togores, Mariano [marqués de Molins] (I883), Bretón de los Herreros. Recuerdos de su vida $y$ de sus obras, Madrid, Imprenta y Fundación de M. Tello.

Rodríguez Cuadros, Evangelina (1998), La técnica del actor español en el Barroco. Hipótesis y documentos, Madrid, Castalia.

Rodríguez SÁnchez de León, Ma José (20I2), «Literatura y política: la función de la literatura en las primeras décadas del siglo XIX», Revista de Literatura, t. LXXIV, n I48, pp. 40I-428. En línea.

Rubio, Enrique (199r), «Martínez de la Rosa: La Conjuración de Venecia, realidad y ficción», en Ermanno Caldera (ed.), Teatro politico spagnolo del primo ottocento, Roma, Bulzoni, pp. $153-160$.

Rubio Jiménez, Jesús (i988), «El realismo escénico a la luz de los tratados de declamación de la época», en Yvan Lissorgues (ed.), Realismo y Naturalismo en la segunda mitad del siglo XIX, Barcelona, Anthropos, pp. 257-286.

Rumeau, Aristide (1939), "Le Théâtre à Madrid à la vieille du Romanticisme (I83I-I834)», en Homenage à Ernest Martinenche, París, D’Artrey, pp. 330-346.

Sala Valldaura, Josep M. (2000), El teatro en Barcelona, entre la Ilustración y el Romanticismo, Lérida, Milenio.

Sánchez, Raquel (2009), Señoras fuera de casa. Mujeres del XIX: la conquista del espacio público, Madrid, Catarata.

Sansano, Gabriel (202I), «Theatre spaces in Barcelona, I800-1850», en Elisa Martí López (coord.), The Routledge Hispanic Studies Companion on the Nineteenth-Century Spain, Londres I Nueva York, Routledge, pp. 325-338.

Saura SÁnchez, Alfonso (2007), «Acercamiento literario y biográfico a Pedro Ángel de Gorostiza y Cepeda: documentos y pistas sueltas», Literatura Mexicana, I8.2, pp- 97-I20.

- (2006), "José Andrew de Covert-Spring, traductor de Dumas: "Ricardo Darlington”, en Àngels Santa Bañeres y Fracisco Lafarga (coords.), Alexandre Dumas y Victor Hugo: viaje de los textos y textos de los viajes, Lérida, Universitat de Lleida, pp. 205-2II. 
- (2003), «El Duque de Braganza, de Covert-Spring, o un drama liberal», en Ignacio Iñarrea de las Heras y María Jesús Salinero (coords.), El texto como encrucijada. Estudios franceses y francófonos, vol. 2, La Rioja, Universidad de la Rioja, pp. 579-59o.

Sepúlveda, Ricardo (1888), El Corral de la Pacheca. Apuntes para la historia del Teatro Español, Madrid, Librería de Fernando.

Simón Palmer, Carmen (2002), Actividades públicas de las madrileñas en la I República, Madrid, Instituto de Estudios Madrileños.

Solís, Dionisio (1828), Camila, tragedia en 5 actos, Madrid, Imp. de I. Sancha.

Soria Tomás, Guadalupe (2020a), «Héroes para la libertad. Escenificaciones de Andrés Prieto (I820-I826)», Cuadernos de Ilustración y Romanticismo, no 26, pp. I65-187. En línea.

- (2020b), «La apertura de la Cátedra de Declamación en la Escuela Nacional de Música. Matilde Díez y Teodora Lamadrid (1874-1896)», Revista de historiografía, no 34 pp. 369-40o. En línea.

- (2015), «L'escola d'interpretació dels Romea-Díez. Actuar i formar actors a la fi del segle XIX», en Antònia Amo y Albert Mestres (eds.), L'intèrpret del teatre naturalista a l'escena digital, Valencia, PUV, pp. 49-66.

- (2010), La formación actoral en España. La Real Escuela Superior de Arte Dramático (I83II857), Madrid, Fundamentos.

- (2009), "La Junta de Reforma de Teatros y la instrucción actoral (I799-I804)», Acotaciones, $\mathrm{n}^{\circ}$ 23, pp. 9-32.

- (2008), La formación actoral en España desde la tentativas ilustradas a la Ley Moyano: La Escuela de Declamación Española. Tesis doctoral. Dpto. Humanidades. UC $\mathrm{U}_{3} \mathrm{M}$.

SuÁrez, Juan Antonio y Roca y Cornet, Joaquín (I83I), Composiciones poéticas a la célebre actriz Concepción Rodríguez, Barcelona, Imprenta de la Viuda e Hijos de Gorchs.

SubirÁ,José (1950), El Teatro del Real Palacio (1849-I85I), Madrid,Instituto Español de Musicología. Suero Roca, María Teresa (1997), El teatre representat a Barcelona, vol. 4, Barcelona, Institut del Teatre. 